\title{
Opposing Roles of apolipoprotein E in aging and neurodegeneration
}

\author{
Eloise Hudry ${ }^{1} \oplus$, Jacob Klickstein ${ }^{1}$, Claudia Cannavo², Rosemary Jackson², Alona Muzikansky ${ }^{3}$, Sheetal Gandhi, \\ David Urick', Taylie Sargent ${ }^{1} \mathbb{\infty}$, Lauren Wrobleski ${ }^{1}$, Allyson D Roe ${ }^{1}$, Steven S Hou', Kishore V Kuchibhotla ${ }^{4}$, \\ Rebecca A Betensky ${ }^{3}$, Tara Spires-Jones², Bradley T Hyman ${ }^{1}$
}

\begin{abstract}
Apolipoprotein E (APOE) effects on brain function remain controversial. Removal of APOE not only impairs cognitive functions but also reduces neuritic amyloid plaques in mouse models of Alzheimer's disease (AD). Can APOE simultaneously protect and impair neural circuits? Here, we dissociated the role of APOE in AD versus aging to determine its effects on neuronal function and synaptic integrity. Using two-photon calcium imaging in awake mice to record visually evoked responses, we found that genetic removal of APOE improved neuronal responses in adult APP/ PSEN1 mice (8-10 mo). These animals also exhibited fewer neuritic plaques with less surrounding synapse loss, fewer neuritic dystrophies, and reactive glia. Surprisingly, the lack of APOE in aged mice (18-20 mo), even in the absence of amyloid, disrupted visually evoked responses. These results suggest a dissociation in APOE's role in AD versus aging: APOE may be neurotoxic during early stages of amyloid deposition, although being neuroprotective in latter stages of aging.
\end{abstract}

DOI 10.26508/Isa.201900325 | Received 29 January 2019 | Revised 5 February 2019 | Accepted 6 February 2019 | Published online 13 February 2019

\section{Introduction}

Apolipoprotein E (APOE) in the central nervous system (CNS) has been the focus of study for two reasons: it is the most abundantly expressed apolipoprotein in the CNS (Bjorkhem \& Meaney, 2004; Huang \& Mahley, 2014), and inheritance of the E4 allele of the APOE gene profoundly impacts the risk for Alzheimer's disease (AD), exacerbating amyloid deposition and worsening cognition and synapse loss. We, therefore, sought to examine the effect of APOE depletion on neuronal function and synaptic integrity in adult or aged mice in both physiological and pathophysiological contexts.

As the primary CNS apolipoprotein, APOE is responsible for much of the regulation of the brain lipid metabolism, particularly the transfer of cholesterol and phospholipids from glial cells to neurons (Boyles et al, 1985; Pitas et al, 1987; Pfrieger \& Ungerer, 2011). During adulthood, neurons rely on cholesterol from glial cells for many processes; thus APOE plays an important role in modulating synapse growth, stabilization, and renewal in a physiological context (Holtzman \& Fagan, 1998; Mauch et al, 2001). APOE is also involved in removing cholesterol and lipids from the CNS, therefore controlling the clearance of cellular debris and promoting remyelination in the aged CNS and some neurodegenerative diseases (Mahley, 1988; Zlokovic, 2011; Cantuti-Castelvetri et al, 2018). Other functions of APOE in the neural tissue include buffering oxidative stress (Evola et al, 2010; Chen et al, 2015) and preserving the integrity of the blood-brain barrier (Fullerton et al, 2001; HafeziMoghadam et al, 2007; Nishitsuji et al, 2011), further emphasizing the pivotal role of APOE in maintaining brain homeostasis.

Previous studies have observed that a complete lack of APOE in murine models leads to cognitive impairment when compared with wild-type mice (Gordon et al, 1995; Masliah et al, 1997; Kitamura et al, 2004; Trommer et al, 2004; Yang, Gilley et al, 2011a; Zerbi et al, 2014), whereas others failed to detect similar deficits (Hartman et al, 2001; Bour et al, 2008). A recent case study of a 40-yr-old man with a complete absence of APOE expression initially reported normal cognitive function (despite dramatic hypercholesterolemia [Mak et al, 2014]), but a second in-depth evaluation showed some evidence of cognitive impairment (Cullum \& Weiner, 2015). Whether these discrepancies result from the use of different cognitive tasks or from the age of the animals and subjects included in each study is unclear, but there is no doubt that further investigation of the specific impact of APOE on neuronal function in vivo remains an important unmet goal.

In the context of disease, APOE was identified more than two decades ago as a significant modulator of the risk for late-onset $A D$ (Wisniewski \& Frangione, 1992; Corder et al, 1993, 1994; West et al, 1994; Hyman et al, 1996; Lippa et al, 1997). APOE is a well-established partner of amyloid $\beta(A \beta)$ peptides, catalyzing $A \beta$ oligomerization, aggregation in the parenchyma (Holtzman et al, 2000; Fagan et al, 2002; Hashimoto et al, 2012), clearance (Deane et al, 2008; ${ }^{1}$ Alzheimer Research Unit, Department of Neurology, Massachusetts General Hospital and Harvard Medical School, Charlestown, MA, USA ${ }^{2}$ Centre for Discovery Brain
Sciences, UK Dementia Research Institute, and Edinburgh Neuroscience, The University of Edinburgh, Edinburgh, UK ${ }^{3}$ Department of Biostatistics, Harvard T.H. Chan
School of Public Health, Boston, MA, USA ${ }^{4}$ Johns Hopkins University, Baltimore, MD, USA

Correspondence: ehudry@mgh.harvard.edu 
Castellano et al, 2011; Hudry et al, 2013), and recruitment to the synapse (Koffie et al, 2012). More recently, APOE has also been identified as a molecular trigger of the amyloid-dependent neuroinflammatory response via its role as a ligand for the triggering receptor expressed on myeloid cells 2 (TREM2) (Atagi et al, 2015; Yeh et $\mathrm{al}, 2016)$. Disruption of the murine apoE gene in AD transgenic models significantly delays the formation of the so-called "dense core" Thio-S-positive amyloid plaques (Bales et al, 1997; Irizarry, Cheung et al, 2000a), even though substantial load of diffuse amyloid and elevated concentrations of soluble $A \beta$ peptides remain in the parenchyma (Irizarry, Rebeck et al, 2000b). These results suggest that a complete lack of APOE may have a beneficial impact on amyloidopathy, a hypothesis recently validated using an approach by antisense oligonucleotide-based knockdown of APOE in mouse models of amyloidosis (Huynh et al, 2017). However, the consequences of $A P O E$ genetic disruption on neuronal function and synaptic integrity are still being debated. The question remains if APOE can simultaneously protect and impair brain homeostasis. The present study aims to examine both APOE's role in normal physiology and in $A \beta$-induced neurotoxicity. To do so, we investigate how APOE affects neuronal function and synaptic integrity rather than only focusing on amyloid changes.

In this study, we used two-photon calcium imaging in the visual cortex to measure visually evoked neuronal responses (Andermann et al, 2011; Grienberger et al, 2012; Kuchibhotla et al, 2014) and array tomography to assess synapse density at a single-synapse resolution (Koffie et al, 2012; Tai et al, 2012; Kay et al, 2013). We systematically evaluated the impact of the presence or absence of APOE on neuronal function and synaptic integrity in mice that develop plaques (APP/PSEN1 mice expressing both the human mutated Amyloid precursor protein, APP, and presenilin-1, PSEN1, genes) and those without increased amyloidosis (wild-type). Our results demonstrate that in the context of amyloid pathology, APOE enables $A \beta$-dependent neuronal dysfunction and synaptotoxicity and a dramatic protective effect is observed by $A p o E^{\text {null }}$. By contrast, APOE also appears as an important factor to preserve brain function during aging, even in the absence of amyloid deposition. These findings, therefore, dissociate APOE's role towards amyloid neuropathological changes versus normal aging and warrant further consideration of the impact of APOE on neuronal function in addition to its effect on amyloid.

\section{Results}

\section{Disruption of visually evoked responses in transgenic mice model of amyloidosis}

To establish how APOE modulates neuronal function and amyloiddependent dysfunction in vivo, we recorded neuronal calcium transients triggered by visual stimulation in wild-type, APOE ${ }^{\text {null, }}$ APP/PSEN1, and APP/PSEN1/APOE ${ }^{\text {null }}$ mice (Fig 1A). The study of neuronal dysfunction in the visual cortex is relevant to $A D$, as deficits in central sensory processing have been reported in the disease, particularly at advanced stages (Cronin-Golomb et al, 1991; Bublak et al, 2011). The visual area V1 is also easily accessible for intra-vital calcium imaging (Andermann et al, 2011) and constitutes the output of a relatively simple circuitry downstream of the retina and the lateral geniculate nucleus within the thalamus (Seabrook et al, 2017), therefore facilitating the recording of neuronal responses to well-controlled sensory stimuli. In addition, two age groups were included in our study (8-10-mo-old "adult" mice and
A

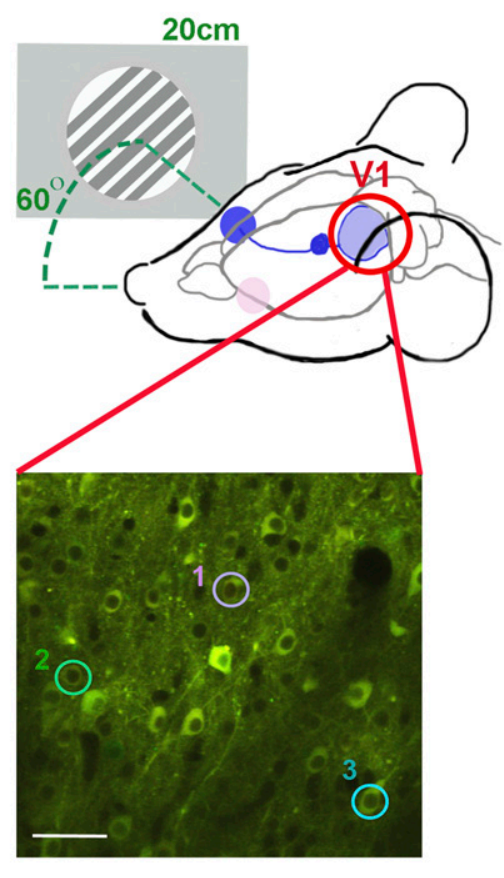

B

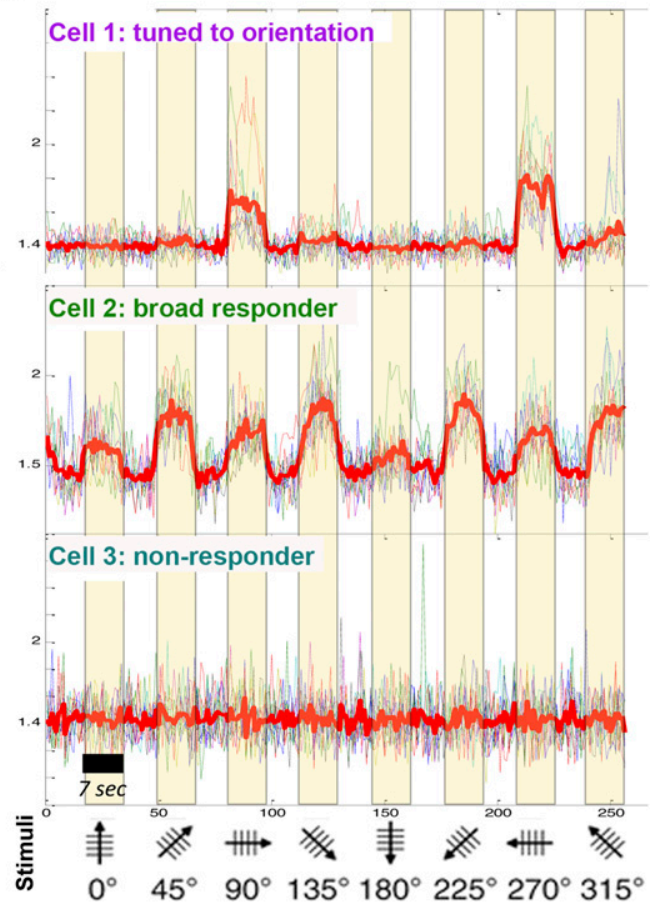

Figure 1. Experimental setting for in vivo recording of visually evoked responses.

(A) Calcium transients were recorded in the primary visual cortex V1 while presenting eight different drifting gratings to the contralateral eye (screen-eye distance, $20 \mathrm{~cm}$; screen-midline angle, 60 Åã). The lower panel shows a representative in vivo twophoton image of AAV-CBA-YC signal detected in neurons one month after AAV stereotaxic injection. (B) Examples of averaged traces for three neurons individually selected in (A) show that the responses are highly heterogeneous within the same field of view, from nonresponsive (cell \#3) to broadly responsive (cell \#2) and neuron responding selectively to a particular orientation of the stimulus (cell \#1). Bar graph: $100 \mu \mathrm{m}$. 
18-20-mo-old "aged" mice) to determine the impact of age, genotype, and the interaction of both parameters (Fig S1A). We could record robust neuronal responses to the visual stimuli in all experimental groups. In our stimulation protocol, responding cells were detected in the primary visual area (mean $=6.89 \pm 1.05 \%$ for wild-type littermates; $13.76 \pm 2.13 \%$ for the APP/PS1; $9.75 \pm 2.3 \%$ for the $A P O E^{\text {null }}$; and $10.58 \pm 1.53 \%$ for the APP/PS1/APOE ${ }^{\text {null }}$ mice, Fig S1A and B). Within the same field of view, a wide range of different response patterns was observed, including nonresponsive cells (no correlation between calcium transients and visual stimulation), broadly responsive cells (increased firing simultaneously to any stimulus), and visually tuned neurons responding to a specific orientation and/or direction of the visual stimulus (Fig 1B). There was no statistical difference between the percentage of "responding cells" among the experimental groups (Fig 2A, $P=0.0682$ ), with variability depending whether or not the region of interest (ROI) considered was exactly located within the primary visual cortex area or at the edge of it (Fig S2).

When establishing our protocol, we observed that in contrast to the broadly tuned cells that responded to any stimuli, occasional neurons systematically fired when the stimuli went off (which we defined as "off-responders," Fig 2B), a phenomenon previously described when recording visual responses in awake animals (Jin et al, 2008; Liang et al, 2008). When we calculated the percentage of "off-responding" neurons in comparison with the overall number of responding cells within the same fields of view, we observed a significant increased proportion of "off-responders" specifically in APP/PSEN1 mice (16.57 $\pm 4.68 \%$, Kruskal-Wallis test, $P=0.0068$, Fig $2 C$ ), which tended to be exacerbated in aged as compared with adult transgenic APP/PSEN1 animals (even though the difference between "adult" and "aged" APP/PSEN1 did not reach statistical significance, Fig S3). Intriguingly, the percentage of off-responding neurons was much lower in all the other groups considered (wildtype: $4.32 \pm 1.27 \%$; APOE $^{\text {null }}: 4.68 \pm 1.19 \%$; and APP/PSEN1/APOE ${ }^{\text {null }}: 3.2 \pm$ $0.84 \%$ ), and especially in APP/PSEN1/APOE ${ }^{\text {null }}$ mice lacking apoe expression, suggesting that $A P O E^{\text {null }}$ mice normalizes an alteration from normal physiology observed in APP/PSEN1 mice.

Apoe genetic ablation in adult APP/PSEN1 mice restores visual selectivity but sensitizes the brain towards age-associated neuronal dysfunction.

To gain further insight into the functional integrity of the visual network between wild-type, APOE ${ }^{\text {null }}$, APP/PSEN1, and APP/PSEN1/ $A P O E^{\text {null }}$ mice, we then compared the direction selectivity index (DSI) and orientation selectivity index (OSI) between these groups (Fig 3 A and B). DSI and OSI represent quantifiable measurements of the ability of visual neurons to respond to a principal orientation or direction of a visual stimulus as compared with others, and higher DSI and OSI values correspond to a more specific tuning to the stimulation. Of importance, this functional feature (the tuning of visual neurons to stimulation) has been previously reported to be impaired in mouse models of amyloidopathy (Grienberger et al, 2012). After fitting a linear mixed model with "genotype" and "age" as fixed effect and "mouse" as random effect, we demonstrated that the log-adjusted DSI and OSI were significantly associated with the genotype ( $P=0.0013$ for DSI and $P=0.0076$ for OSI) and with the age of the mice ( $P=0.0325$ for DSI and $P=0.0068$ for OSI). In particular, the average of both DSI and OSI was lower in APP/PSEN1 mice as compared with wild-type animals $(P=0.0002$ and $P=0.0008$, respectively), therefore demonstrating impaired tuning to visual
A

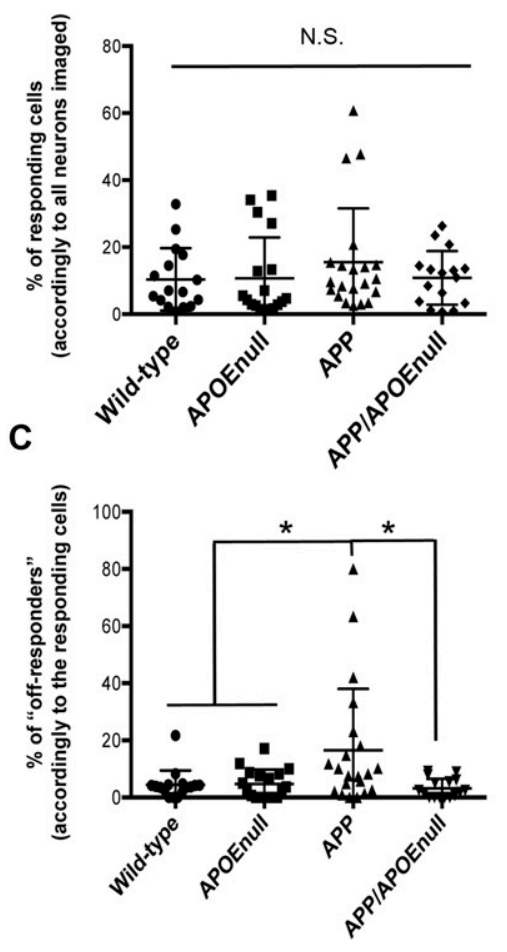

B

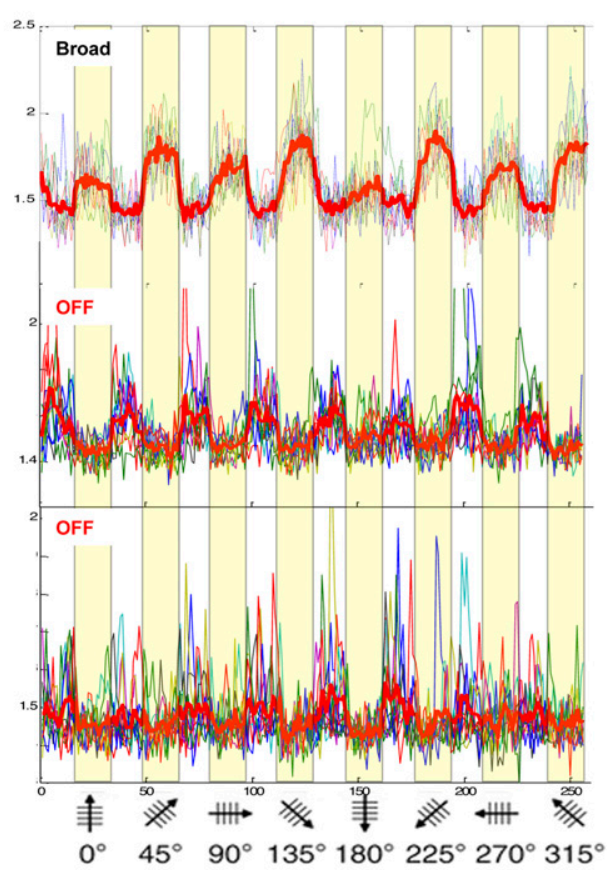

Figure 2. "Responders" and "off-responders" proportions.

(A) Scatter dot plot representing the percentage of neurons responding to visual stimulation among all neurons analyzed in each animal. (B) Representative traces or visually evoked neuronal responses showing the concomitant presence of broad and offresponding cells in the same field of view during the same imaging session. (c) Scatter dot plot of the percentage of "off-responding" cells across genotypes (calculated accordingly to the number of responsive neurons within the same fields of view). $n=18$ wildtype, $n=13$ APOE $^{\text {null }}, n=18$ APP/PSEN1, and $n=16$ APP / APOE ${ }^{\text {null }}$ mice (adult and old cohorts); Kruskal-Wallis test followed by post hoc Dunn's Multiple comparison test; ${ }^{*} P<0.05$. 
A

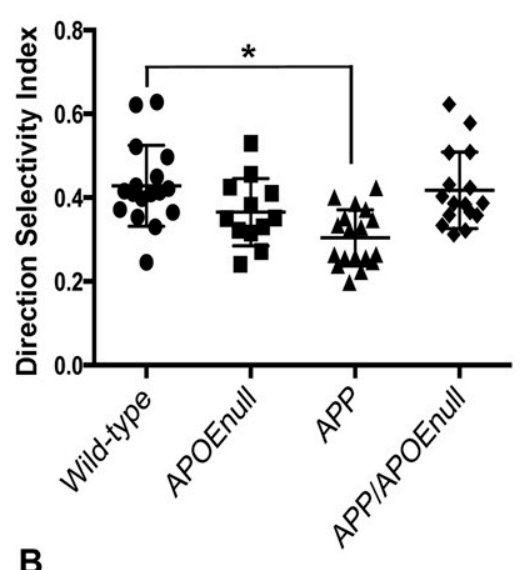

B

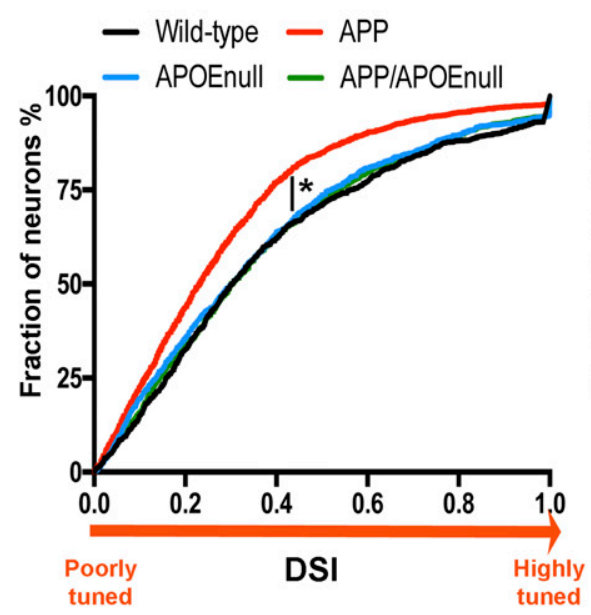

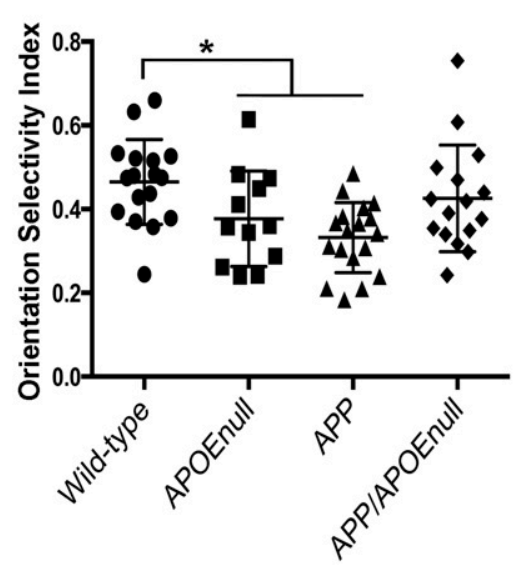

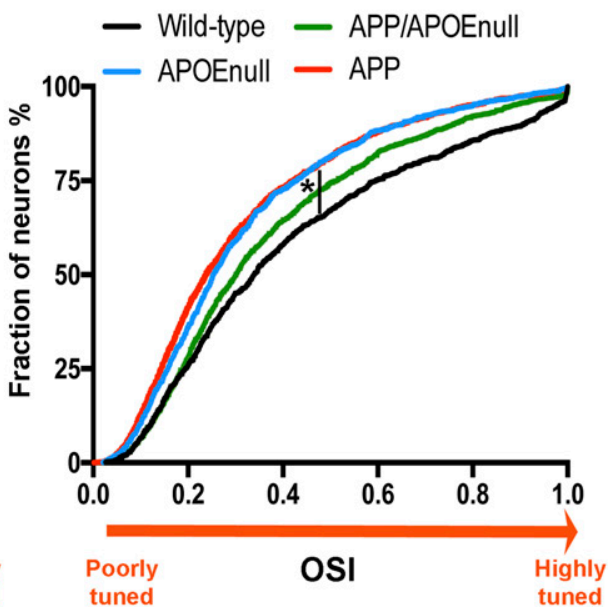

Figure 3. Tuning to visual stimuli in wild-type, $A{ }^{\text {null }}$, APP/PSEN1, and APP/PSEN1/APOE ${ }^{\text {null }}$ mice. (A) Scatter dot plots representing the DSI (left panel) and OSI (right panel) calculated after recording visually evoked response in wild-type, APOE ${ }^{\text {null }}$, APP / PSEN1, and APP/PSEN1/APOE $E^{\text {null }}$ mice. (B) Cumulative distributions of DSI and OSI calculated for all responding neurons showing a shift towards an increased proportion of poorly tuned neurons in APP / PSEN1 as compared with the other genotypes, with the exception of the OSI distribution in APOE ${ }^{\text {null }}$ mice. $n=$ 18 wild-type, $n=13$ APOE $^{\text {null }}, n=18$ APP/PSEN1, and $n=$ 16 APP/APOE ${ }^{\text {null }}$ mice (adult and old cohorts); linear mixed model after log-transformation of the data; ${ }^{*} P<$ 0.05 . stimulation in this model of amyloidosis. This was not the case between the control and APP/PSEN1/APOE ${ }^{\text {null }}$ groups ( $P=0.4091$ and $P=0.1584)$. These results, therefore, demonstrated that the absence of APOE largely abrogates A $\beta$-dependent neuronal dysfunction in a mouse model of amyloidosis. However, APOE ${ }^{\text {null }}$ mice still showed a mild decreased OSI average when compared with wild-type controls $(P=0.0294$ ), implying that the complete lack of APOE itself can impact tuning performances.

Pair-wise comparisons between adult and aged mice (Fig S4A) revealed more prominent age-dependent decreases of the OSI values in APP/PSEN1/APOE ${ }^{\text {null }}(P=0.037)$, with a similar but nonsignificant decrease in $\mathrm{APOE}^{\text {null }}(P=0.109)$ mice. No age-dependent change was detected for the control or APP/PSEN1 groups, which respectively presented with high or low OSI means across the lifespan of the mice. The DSI values showed fewer differences with only a significant decreased average of the DSI detected in aged APP/PSEN1 mice $(P=0.0445)$. The higher sensitivity of OSI to discriminate changes in visual tuning can be explained by the fact that the OSI was calculated based on the tuning discrimination between the "favorite" orientation as compared with three other orientations, whereas the DSI was calculated based on preferential firing for one direction as compared with the opposite one. When compared with age-matched littermates (Fig S4B), both adult and aged APP/PSEN1 mice were significantly impaired for OSI and DSI ( $P=0.011$ for DSI and $P=0.0012$ for OSI when comparing adult APP/PSEN1 and littermates; and $P=$ 0.022 for DSI and $P=0.042$ for OSI when comparing aged APP/PSEN1 and littermates). However, only the OSI values were significantly diminished in aged $\mathrm{APOE}^{\text {null }}$ mice as compared with aged controls $(P=0.04)$. The averaged OSI in aged APP/PSEN1/ApoE ${ }^{\text {null }}$ mice was also lower than wild-type animals, but this difference did not reach significance $(P=0.084)$. These results demonstrated early and pronounced neuronal dysfunction in mice model of $A \beta$ amyloidosis, a phenotype significantly improved in adult mice lacking APOE. However, age-dependent deficits were also detected in older $\mathrm{APOE}^{\text {null }}$ and, to a lesser extent, APP/PSEN1/APOE ${ }^{\text {null }}$ mice. We concluded that APOE is a necessary factor participating in amyloiddependent loss of network integrity, although complete lack of APOE independently triggers mild neuronal dysfunction with age.

\section{Apoe genetic ablation does not impact global amyloid burden but affects the aggregation state of $A \beta$}

To evaluate how the "rescue effect" observed in mice lacking APOE correlated with the level of amyloid pathology, we performed a 
A
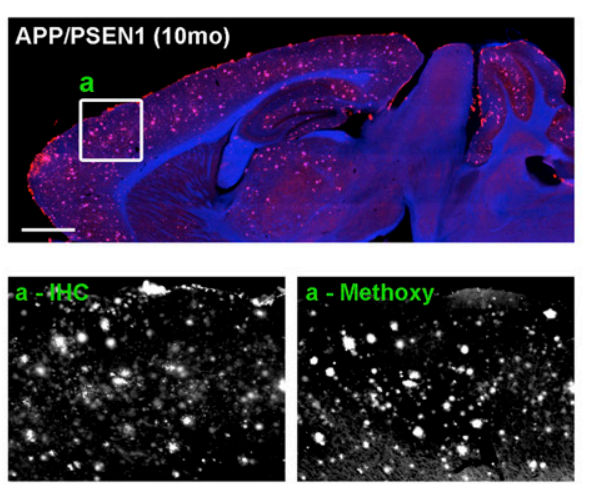

B
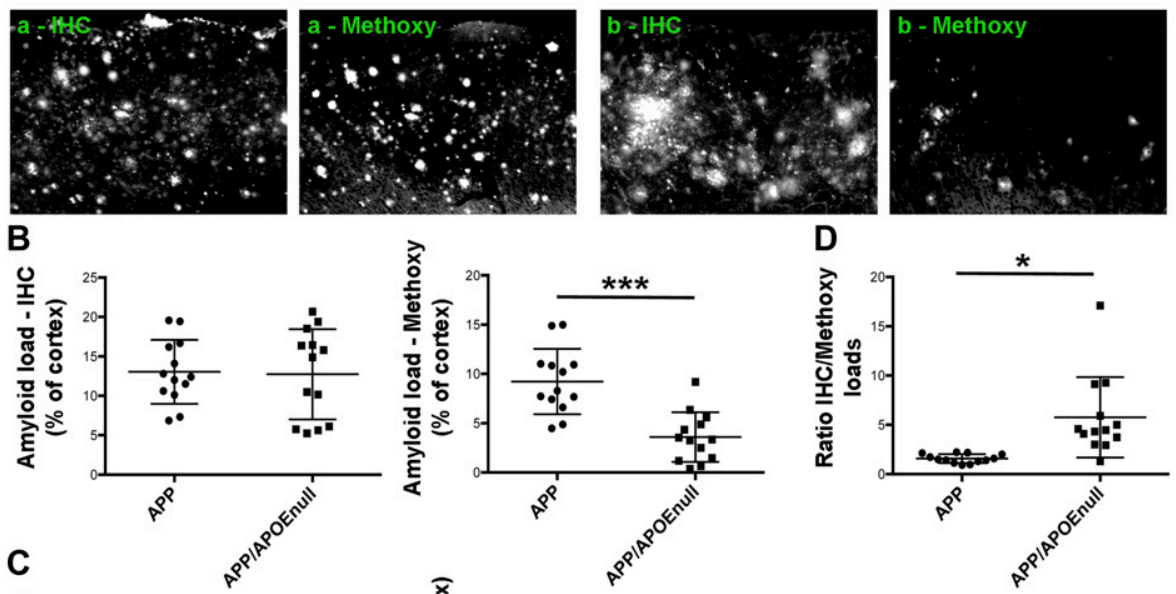

D
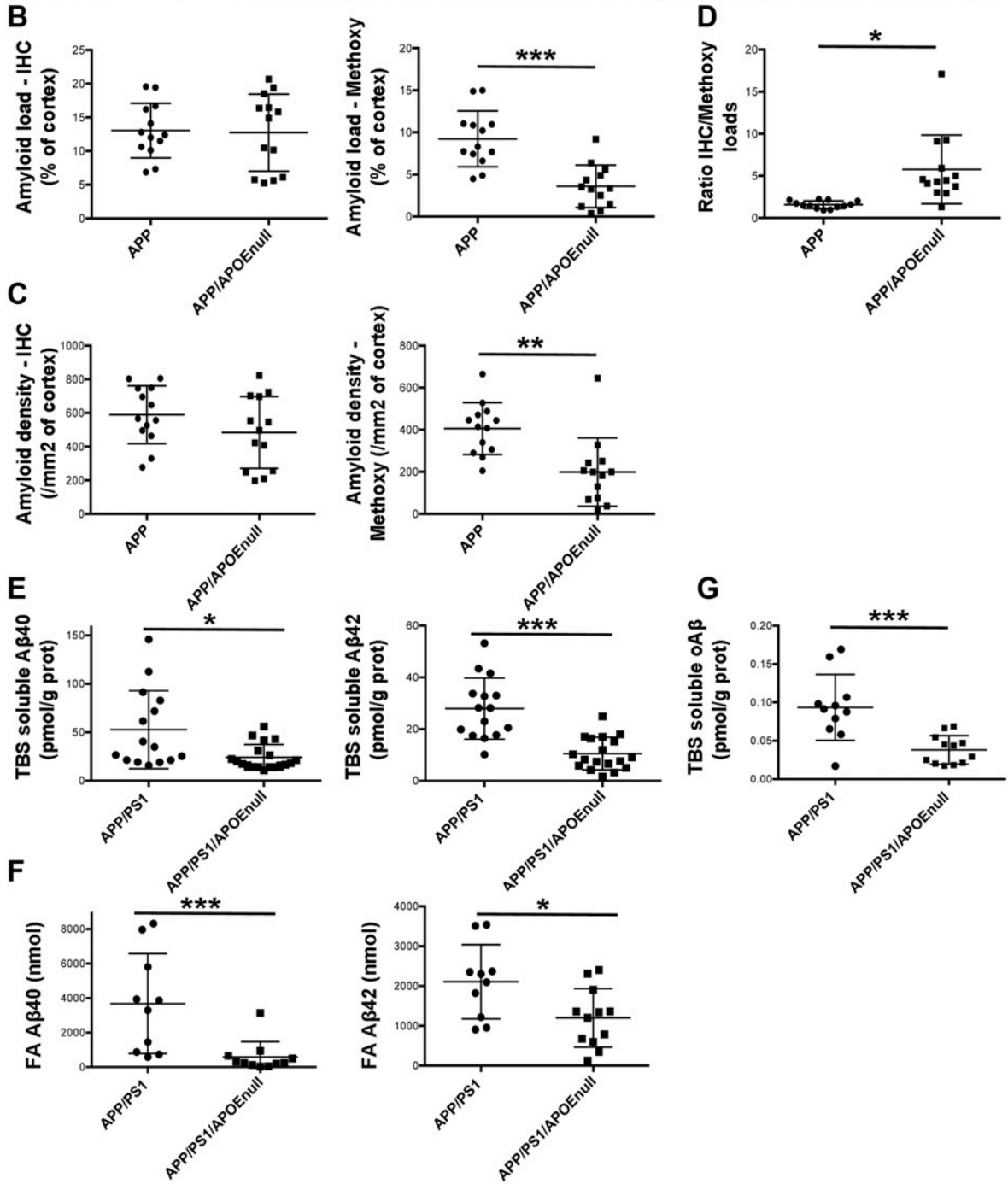

Figure 4. Amyloid pathology in APP/PSEN1 and APP/PSEN1/APOE ${ }^{\text {null }}$ mice.

(A) Representative images of the global amount of amyloid in the cortex of APP/PSEN1 and APP/PSEN1/ APOE $^{\text {null }}$ mice at 10 -mo old after anti-A $\beta$

immunostaining $(\mathrm{IH})$. As shown in the lower panels, the overall load of amyloid was comparable between genotypes, but the amount of dense-core plaques detected with Methoxy-XO4 was greatly diminished in the absence of APOE. (B) Scatter dot plot representing the stereological quantification of amyloid load in APP/PSEN1 and APP/PSEN1/APOE ${ }^{\text {null }}$ animals

(including both adult and aged cohorts) after anti-A $\beta$ immunostaining or Methoxy-XO4 labeling. (c) Scatter dot plots representing the stereological quantification of plaque density in APP/PSEN1 and APP/PSEN1/

APOE $^{\text {null }}$ animals. (D) The ratios of $\mathrm{IH} /$ Methoxy calculated per mouse showed that the amyloid deposits are mostly diffuse in APP/PSEN1/APOE ${ }^{\text {null }}$ mice as compared with APP/PSEN1. (E) The biochemical quantification of the concentrations of TBS-soluble $A \beta 40$ and $A \beta 42$ revealed lower levels of $A \beta$ peptides in mice devoid of APOE as compared with APP/PSEN1 mice (both age groups pooled together). (F) A parallel result was observed when quantifying the levels of FA A $\beta 40$ and $A \beta 42$. (G) A similar difference was observed when the concentration of $A \beta$ oligomers was measured from TBS brain extracts. Scale bar = $1,000 \mu \mathrm{m} . \mathrm{n}=10$ to $18 \mathrm{mice} /$ group; unpaired $t$ test; ${ }^{*} \mathrm{P}<$ $0.05,{ }^{* *} P<0.001,{ }^{* * *} P<0.0005$ stereological analysis of the load and density of amyloid plaques in the cortex of APP/PSEN1 and APP/PSEN1/APOE ${ }^{\text {null }}$ mice. Conventional anti-A $\beta$ immunolabeling detecting all amyloid aggregates revealed that neither the burden nor the density of deposits was significantly different between APP/PSEN1 and APP/PSEN1/APOEnull (Fig $4 A-C$ ). By contrast, a dramatic decrease in the amount of fibrillar deposits stained by Methoxy- $\mathrm{XO}_{4}$ was observed in mice lacking APOE (Fig 5D; $P<0.0001$ and $P=0.0004$, respectively, for Methoxy load and density between APP/PSEN1 and APP/PSEn1/ $A P O E^{\text {null }}$ mice), in agreement with previous reports showing that APOE significantly affects the aggregation state of $A \beta$ neurotoxic species (Irizarry et al, 2000a; Holtzman et al, 2000; Fagan et al, 2002). 
A
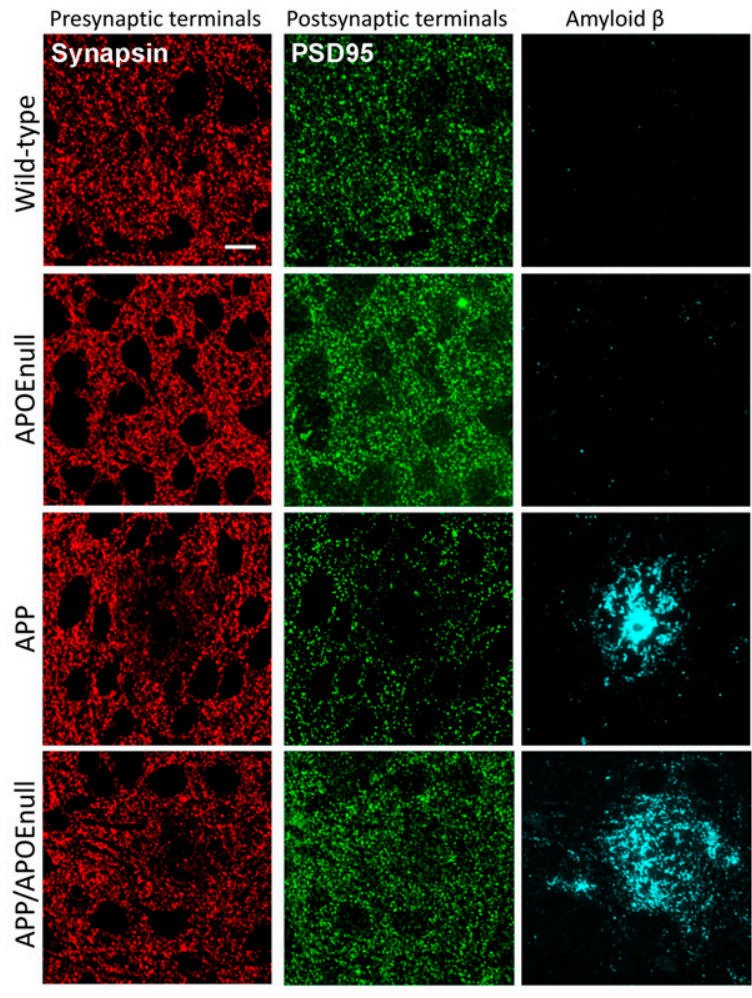

MERGE
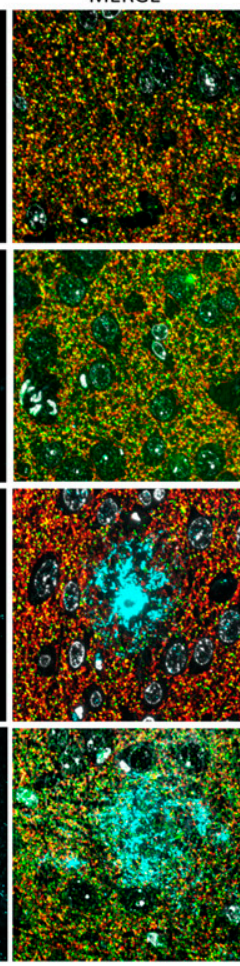

है

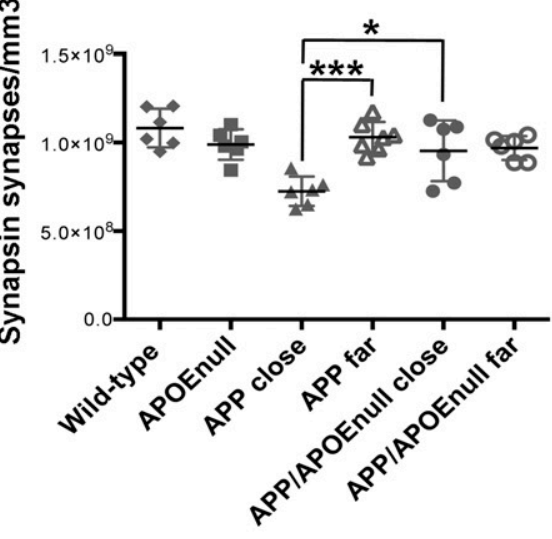

D

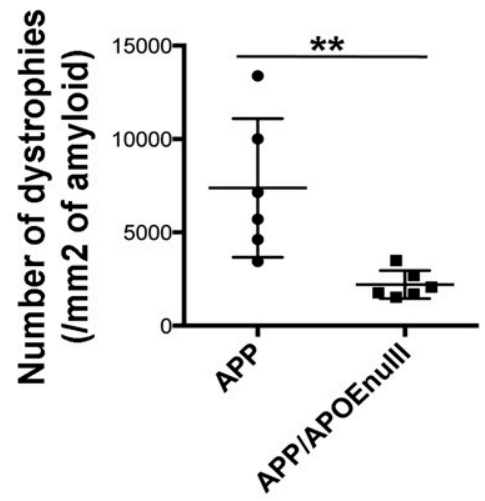

Figure 5. Ab-dependent synaptic loss and neuritic dystrophies in adult APP/PSEN1 and APP/PSEN1/ APOE $^{\text {null }}$ mice.

(A) Representative images of array tomography ribbons after immunostaining for Ab (1C22), presynaptic terminals (antisynapsin I, red), postsynaptic densities (anti-PS95, green), and nuclei (DAPI, blue). It is possible to appreciate how diffuse is the amyloid in the brain of APP/APOE ${ }^{\text {null }}$ mouse as compared with the compact staining observed in the APP mouse. Scale bar $=10 \mu \mathrm{m}$. (B) Scatter dot plots summarizing the density of PSD95 (left panel) and synapsin (right panel)-positive puncta in the cortex of wild-type, APOE ${ }^{\text {null }}$, APP/PSEN1, and APP/PSEN1/ APOE ${ }^{\text {null }}$ mice. A significant decrease in synaptic density was only observed in the close vicinity of amyloid plaques in $A D$ transgenic mice. $n=6$ mice/ group (10-12 mo "adult" cohort); Two-way ANOVA and Tukey's post hoc test. ${ }^{*} P<0.05$ and ${ }^{* \star *} P<0.0001$. (C) Representative images of neuritic dystrophies (arrows) around amyloid plaques observed in APP/ PSEN1 and APP/PSEN1/APOE null mice, showing that most sprouting axons are found in mice expressing endogenous murine apoE. Scale bar $=50 \mu \mathrm{m}$. (D) Scatter dot plot summarizing the stereological quantification of the number of dystrophies observed per area of amyloid (evaluated by immunohistological staining). $\mathrm{n}=6$ mice per group (10-12 mo "adult" cohort); Mann-Whitney test. ${ }^{*} P<0.005$.
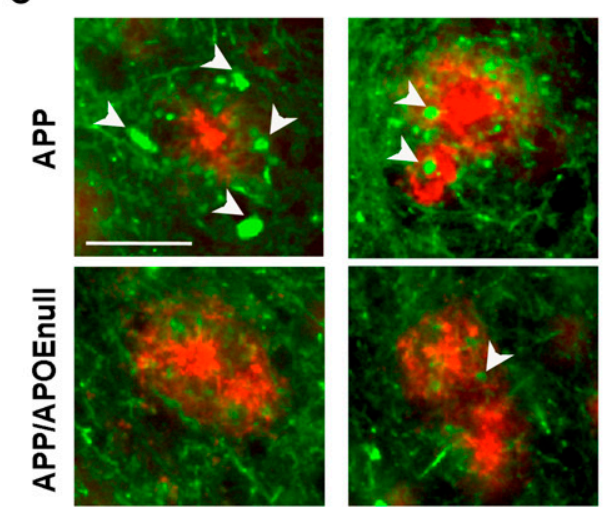
Consequently, the ratio of amyloid load between "all deposits" and dense core plaques was significantly higher in APP/PSEN1/APOE ${ }^{\text {null }}$ as compared with APP/PSEN1 mice (Fig 4D). Within each genotype, the amyloid load progressed between adult and aged mice, but the increase in Methoxy- $\mathrm{XO}_{4}$-positive plaques was not as prominent as the changes observed when both diffuse and compact deposits were analyzed altogether (Fig S5). To complete this analysis, we determined the concentrations of $A \beta 40$ and $A \beta 42$ in the TBS and formic acid (FA) fractions of the brains, and we observed a general decrease in the amounts of A $\beta$ species in APP/PSEN1/APOE ${ }^{\text {null }}$ mice as compared with APP/PSEN1 (Fig 4E-G; $P=0.0169$ and $P<0.0001$, respectively, for TBS soluble $A \beta 40$ and $A \beta 42 ; P=0.0004$ and $P=0.019$, respectively, for FA soluble $A \beta 40$ and $A \beta 42$ ). Interestingly, these differences were essentially due to the substantial levels of amyloid peptides in aged APP/PSEN1 animals (Fig S6A-C), whereas the amounts of both soluble and insoluble $A \beta 40 / 42$ were comparable between the adult cohorts (for which the lack of APOE alleviates A $\beta$ dependent neuronal dysfunction). These data emphasize the weak correlation that exists between the global amount of amyloid and neuronal dysfunction and illustrate the necessity to assess amyloid-dependent neurotoxicity from a functional perspective. No substantial difference in the amount of amyloid pathology was detected between adult APP/PSEN1 and APP/PSEN1/APOE ${ }^{\text {null }}$ mice (except for the presence of dense-core neuritic plaques), even though the absence of APOE in the later rescued the neuronal responses to visual stimuli. These findings strengthen the rationale for down-regulating $A p o E$ expression as a possible therapeutic approach to alleviate $A \beta$-dependent neuronal impairment.

\section{Apoe genetic ablation does not alter the global levels of excitatory and inhibitory neurotransmitter receptors but rescues synaptic integrity near $A \beta$ plaques}

To determine if the functional alterations detected by recording visually evoked neuronal responses in vivo might correlate with changes of the levels of excitatory or inhibitory neurotransmitter receptors at the synapse, we performed a biochemical analysis after preparing synaptoneurosome-enriched fractions from the cortex of adult wild-type, APOE ${ }^{\text {null }}$, APP/PSEN1, and APP/PSEN1/ $A_{P O E^{\text {null }}}$ mice (10-12 mo) (Fig S7). Overall, no significant difference was detected in the levels of $N$-methyl-D-aspartate receptor 1 (NMDAR1), 2A (NMDAR2A), 2B (NMDAR2B), y-aminobutyric acid receptors $A$ (GABAR-A), and $B$ (GABAR-B) between all the experimental groups (Fig S8). These results demonstrate that the neuronal circuitry dysfunction previously observed in APP/PSEN1 mice do not result from a global difference in the levels of excitatory or inhibitory synaptic markers.

Because local loss of synapses is one of the well-established downstream effects of amyloid deposition that may participate in network deterioration (Pozueta et al, 2013; Spires et al, 2005; SpiresJones \& Hyman, 2014; Hong et al, 2016; Arbel-Ornath et al, 2017) and considering that we detected a change in the aggregation state of amyloid deposits in the cortex of APP/PSEN1/APOE ${ }^{\text {null }}$ mice, we tested the hypothesis that the improved visual tuning observed in the absence of APOE could be directly related with a decreased local synaptotoxicity of $A \beta$ peptides present in plaques in those mice. Using the high-resolution imaging technique array tomography, the density of pre- (synapsin) and post-synaptic (PSD95) elements was determined in the cortical mantle of the adult cohort previously imaged. For all plaque-bearing animals (APP/PSEN1 and APP/PSEN1/APOE ${ }^{\text {null }}$ ), the synaptic density in areas of the cortex close $(<10 \mu \mathrm{m})$ and $\operatorname{far}(>35 \mu \mathrm{m})$ from amyloid plaques was independently measured. Total synapsin 1 and PSD95 puncta were used as measurements of synaptic density in the four mouse lines, as previously done in other similar studies (Koffie et al, 2009; Koffie et al, 2012; Kay et al, 2013) (Fig 5A and B). A two-way ANOVA test with distance from the plaque and genotype as variables was used and detected a significant difference across both variables (distance from plaque: $F(1,41)=15.94, P=0.0003$; genotype: $F(3,41)=$ 7.658, $P=0.0004)$. Comparison of individual groups using a Tukey's post hoc test revealed that a 30\% synaptic loss was observed near amyloid plaques in APP/PSEN1 mice (as previously observed [Koffie et al, 2009] and Fig 5B), with an averaged density of PSD95 and synapsin puncta close to plaques of $6.83 \times 10^{8} \pm 2.76 \times 10^{7} / \mathrm{mm}^{3}$ and $7.24 \times 10^{8} \pm 3.14 \times 10^{7} / \mathrm{mm}^{3}$, respectively, as compared with $9.99 \times 10^{8} \pm$ $3.21 \times 10^{7}$ and $10.30 \times 10^{8} \pm 3.26 \times 10^{7}$ synapses $/ \mathrm{mm}^{3}$ far from plaques $(P<0.0001)$. This decrease in synaptic density in the direct vicinity of amyloid in APP/PSEN1 mice was also significant compared with wild-type $\left(9.77 \times 10^{8} \pm 3.63 \times 10^{7} \mathrm{PSD} 95 \mathrm{puncta} / \mathrm{mm}^{3}\right.$ and $10.82 \times 10^{8} \pm 4.46 \times 10^{7}$ synapsin puncta $\left./ \mathrm{mm}^{3} ; P<0.0001\right)$ and $\operatorname{APOE}^{\text {null }}\left(9.83 \times 10^{8} \pm 2.42 \times 10^{7} \mathrm{PSD} 95 \mathrm{puncta} / \mathrm{mm}^{3}\right.$ and $9.89 \times 10^{8} \pm$ $3.54 \times 10^{7}$ synapsin puncta $/ \mathrm{mm}^{3}, P<0.0001$ ) controls. Interestingly, no drop of the synaptic density was detected close to plaques in APP/PSEN1/APOE ${ }^{\text {null }}$ mice $\left(8.51 \times 10^{8} \pm 76.51 \times 10^{7}\right.$ PSD95 puncta/ $\mathrm{mm}^{3}$ and $9.53 \times 10^{8} \pm 7.03 \times 10^{7}$ synapsin positive puncta $\left./ \mathrm{mm}^{3}\right)$, which was significantly higher than the synaptic density measured in the vicinity of amyloid deposits in APP/PSEN1 mice $(P=0.0345)$, and comparable with wild-type and $A P O E^{\text {null }}$ animals. These results, thus, imply that the presence of both $A \beta$ and APOE is necessary to observe synaptic collapse in AD transgenic mice and that abolishing apoE expression suffices to rescue amyloid-dependent synaptic loss and the functional impairments observed in APP/ PS1 mice. Intriguingly, when the accumulation of $A \beta$ at the synapse in APP/PSEN1 and APP/PSEN1/APOE ${ }^{\text {null }}$ was measured as the percentage of pre- and post-synaptic densities co-localizing with amyloid, no significant difference could be observed between those groups (Fig S9A), thus challenging the concept of APOE acting as a chaperone mediating $A \beta$ accumulation at the synapse. In addition, the synaptic volume decreased significantly close to plaques in APP/PSEN1 mice, a parameter that remained unchanged in the absence of APOE (Fig S9B).

\section{The absence of APOE decreases A $\beta$-associated neuritic anomalies and glial reactivity}

To complete our evaluation of the impact of APOE on A $\beta$-dependent neurotoxic effects in the microenvironment of amyloid plaques, we performed a stereological analysis of the density of neuritic dystrophies around each deposit (Fig 5C) and A $\beta$-dependent glia reactivity in the cortex of APP/PSEN1 and APP/PSEN1/APOE null animals (adult cohort). Although numerous abnormal neurites were generally associated with amyloid plaques in APP/PSEN1 mice, they were seldom in APP/PSEN1/APOE ${ }^{\text {null }}$ animals (Fig 5D, $P=0.043)$. In addition, when we evaluated the number of reactive 
astrocytes (Glial fibrillary acidic protein, GFAP, positive) and microglia (Iba1 positive) clustered around amyloid aggregates in APP/PSEN1 and APP/PSEN1/APOE ${ }^{\text {null }}$ mice, we observed a significant decreased density of both glial cell types in animals lacking APOE (Fig 6, $P=$ 0.0006 for microglia and $P=0.0012$ for astrocytes). These results not only establish APOE as an essential modulator of amyloid deposition but also demonstrate its strong impact on a large panel of $A \beta$ associated neurotoxic events and downstream inflammatory reactions in the local vicinity of amyloid plaques. Whether or not these effects are a direct consequence of the change in the aggregation state and toxicity of $A \beta$ or indirectly related to the impact of a lack of APOE on microglia/astroglia function remains to be determined.

\section{Discussion}

Neuronal dysfunction and loss of synaptic integrity are tightly associated with aging and AD cognitive decline, but understanding the molecular bases of those changes and identifying possible modulators remain as important challenges to overcome. APOE, the major apolipoprotein of the brain and most important genetic contributor to the sporadic form of AD (Wisniewski \& Frangione, 1992; Corder et al, 1993, 1994; West et al, 1994; Hyman et al, 1996; Lippa et al, 1997), is a well-established partner of amyloid $\beta$ peptides and has been shown to directly impact the aggregation, deposition, and clearance of those neurotoxic species (Holtzman et al, 2000; Fagan et al, 2002; Deane et al, 2008; Castellano et al, 2011; Hashimoto et al, 2012; Koffie et al, 2012; Hudry et al, 2013). Although those findings clearly emphasize the pivotal role of APOE in AD neuropathological changes, the field is still divided as to whether or not clinical benefit could be achieved by reducing the levels of APOE (Koldamova et al, 2005; Bien-Ly et al, 2012; Liao et al, 2014; Lane-Donovan et al, 2016; Zheng et al, 2017). In addition, previous studies have described that a complete lack of APOE in a physiological context may lead to a loss of brain function during aging. The question, therefore, is how can we disambiguate the function of APOE in maintaining brain resilience during aging while also participating in $A \beta$-induced neurotoxicity?

By recording visually evoked neuronal responses in awake mice, we were able to demonstrate that a complete absence of APOE restores neuronal function in adult APP/PSEN1 animals (decreased "off-responding" cells and increased OSI and DSI), so that the efficacy of induced responses is comparable between wild-type and APP/PSEN1/APOE ${ }^{\text {null }}$ animals. In addition, the lack of APOE in $A D$ mice preserves synaptic and neuritic integrity around plaques and decreases amyloid-associated glial immunoreactivity. Despite these beneficial effects, the idea of knocking-down APOE expression to improve $A D$ neuropathological hallmarks remains controversial because previous reports have shown that APOE ${ }^{\text {null }}$ animals present with some cognitive deficits, electrophysiological alterations, and functional connectivity changes when compared with wild-type mice (Masliah et al, 1997; Kitamura et al, 2004; Trommer et al, 2004; Yang et al, 2011a; Zerbi et al, 2014). Here, we confirm that genetic ablation of APOE impairs visually evoked responses of aged $\mathrm{APOE}^{\text {null }}$ and APP/PSEN1/APOE ${ }^{\text {null }}$ mice as compared with controls. Taken together, we demonstrate that apoE genetic disruption alleviates $A \beta$-associated neurotoxicity early but sensitizes the brain towards age-dependent neuronal dysfunction. Discrepancy between our results and previous reports may result from the experimental settings used, as we assessed neuronal function using a relatively simple sensory circuit within the brain as compared with more complex behavioral tasks.

Data in the human population are essentially missing, with only one case study published so far reporting "below-average" cognition and memory performances in an individual with a complete lack of APOE protein in the brain (Cullum \& Weiner, 2015). Because of the relatively young age of the individual, it is hard to predict if
A
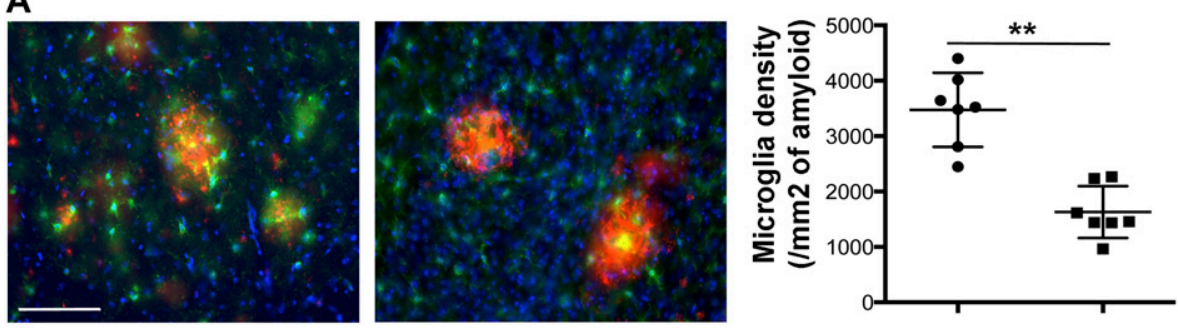

B

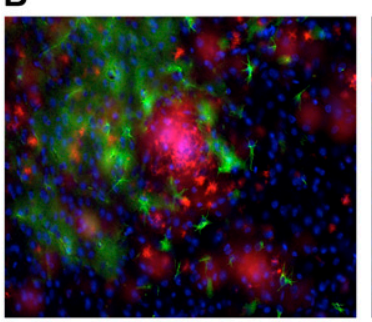

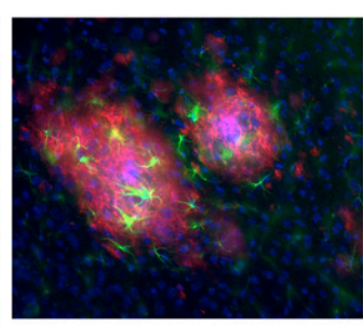

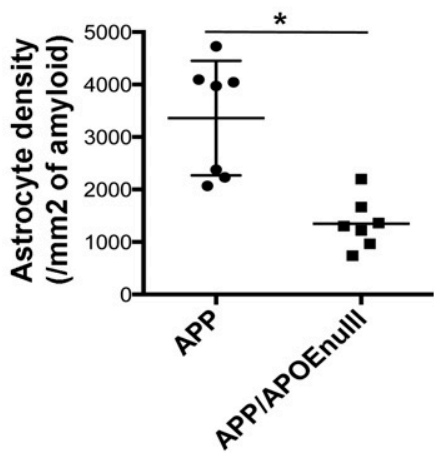

Figure 6. Decreased glial reactivity in APP/PSEN1 mice lacking APOE.

(A) RepreseAPP/PSEN1 and APP/PSEN1/APOE ${ }^{\text {null }}$ adult mice. (B) Representative images (left panel) and stereological evaluation (right panel) of the density of GFAP-positive astrocytes (green) around amyloid deposits (red, after staining using a rabbit anti-A $\beta$ antibody, IBL) in APP/PSEN1 and APP/PSEN1/APOE ${ }^{\text {null }}$ adult mice. In each case, the total number of Iba1-positive microglia or GFAP-positive astrocytes present in less than $50 \mu \mathrm{m}$ around a plaque was reported to the surface of the plaque. Scale bar = $100 \mu \mathrm{m} . \mathrm{n}=7$ mice/group (10-12 mo "adult" cohort); Mann-Whitney test. ${ }^{*} P<0.005,{ }^{* *} P<0.001$. 
the absence of APOE will lead to exacerbated cognitive decline later on, similar to what is observed in animal models. Alternative strategies to inhibit the detrimental impact of APOE in disease while preserving its physiological role in maintaining brain homeostasis have already been attempted. For example, intraperitoneal injections of $A \beta 12-58 \mathrm{P}$, a modified $A \beta$ peptide homologous to the binding side of APOE on $A \beta 40 / A \beta 42$ peptides that crosses the blood-brain barrier, is able to disrupt the interaction between APOE and $A \beta$, reduce the formation of fibrillar aggregates, alleviate $T$ pathology in triple transgenic mice (PS1M146V, APPSwe, and tauP30IL), and improve behavioral deficits (Yang et al, 2011b; Liu et al, 2014). Reducing the amount of APOE specifically in the brain tissue (and not in the periphery) could be another alternative. The recent characterization of the bEKO mouse model by Lane-Donovan and colleagues (Lane-Donovan et al, 2016), which fortuitously lacks APOE in the brain but shows normal levels in the plasma, suggests that this may be the case, as these animals do not show any cognitive deficits as compared with APOE ${ }^{\text {null }}$ mice. However, the clinical translation of this discovery may prove difficult to achieve considering that various neural cell types express APOE (astrocytes, microglia, and endothelial cells). Interestingly, the work by Zheng and colleagues demonstrated that the sole deletion of APOE in astrocytes ameliorates the spatial learning and memory deficits of APP/PSEN1 mice (Zheng et al, 2017), eventually suggesting that targeting APOE in the "right cells" (assuming that APOE derived from astrocytes, microglia, or other cells within the brain has different biological properties and functions) may trigger clinical improvement.

Importantly, the "rescue effect" observed in the absence of APOE did not directly correlate with a significant change in the global amount of amyloid pathology in the brain of our adult cohort (assessed by conventional immunostaining or by quantification of $A \beta$ by ELISA), but rather with a specific decrease in dense-core Methoxy-positive deposits in APP/PSEN1/APOE ${ }^{\text {null }}$ mice (both in adult and aged groups). Of note, the initial load of fibrillar amyloid at baseline is especially abundant in the model we used, the APP / PSEN1 strain, because of the presence of the Swedish APP (KM670/ $671 \mathrm{NL}$ ) and $\delta 9$ PS1-mutated transgenes. It is, therefore, conceivable that the impact of APOE deficiency may be less significant in other models of amyloidopathy that only carry a mutated APP allele. Nevertheless, the shift in the aggregation state of amyloid between APP/PSEN1 and APP/PSEN1/APOE ${ }^{\text {null }}$ has been reported in other studies (Bales et al, 1997; Irizarry et al, 2000a) and essentially reproduces the morphological difference between $\beta$-pleated sheet deposits (labeled with Thioflavin-S) mostly observed in AD patients and diffuse plaques detected in non-demented individuals (Dickson, 1997; Urbanc et al, 2002). This conformational change of extracellular amyloid is relevant to the disease as fibrillary neuritic plaques are associated with deleterious effects on the surrounding neuropil, such as the presence of dystrophic neurites and recruitment of reactive glial cells (Masliah et al, 1990; Knowles et al, 1999; Vehmas et al, 2003), which are absent around more diffuse aggregates observed in cognitively normal individuals and in our APP/PSEN1/APOE ${ }^{\text {null }}$ animals. The underlying mechanisms remain incompletely understood, but in vitro and in vivo studies have previously shown that APOE forms stable complexes with $A \beta$ (Naslund et al, 1995), directly co-deposits in plaques (Namba et al,
1991), modulates $A \beta$ oligomerization (Hashimoto et al, 2012; Garai et al, 2014), and converts amyloid protofibril to fibril (Hori et al, 2015), which all could result in the observed changes in plaque morphology. Further comparison of the profile of $A \beta$ oligomers, which are especially concentrated around amyloid plaques and have been shown to trigger neurotoxicity (Walsh \& Selkoe, 2007; Arbel-Ornath et al, 2017; Yang et al, 2017), may give additional clues to understand the beneficial impact the lack of ApoE on $A \beta$ dependent neuronal function and synaptotoxicity.

It is possible that some of the protective effects we observed in APP/PSEN1/APOE ${ }^{\text {null }}$ mice arise independently from the change observed in the aggregation state of $A \beta$. In particular, the decreased glial reactivity in $A P P / P S E N 1 / A P O E^{\text {null }}$ mice could result from a direct impact of APOE on the biology of microglia and astrocytes in the context of $A D$, even in the presence of $A \beta$ neurotoxic species. The APOE-TREM2 pathway has recently been identified as a major switch triggering a phenotypic change in microglia in the context of neurodegeneration (Atagi et al, 2015; Yeh et al, 2016; Krasemann et al, 2017). Upon activation of this cascade, microglial cells become chronically inflammatory and lose their homeostatic signature, a phenomenon that is not present when the endogenous expression of apoe was shut down specifically in microglia. Considering that activated neuroinflammatory microglia have also been shown to control the conversion of resting (A2) to reactive astrocytes (A1) (Liddelow et al, 2017), the inhibition of the TREM2-APOE pathway in APP/PSEN1/APOE ${ }^{\text {null }}$ mice could explain the overall decrease of glial reactivity independently of the decreased density of neuritic plaques in those mice.

Finally, our array tomography data emphasize the importance of APOE in driving $A \beta$-associated synapse loss. While the density of synapsin and PSD95 puncta was dramatically reduced in the vicinity of amyloid deposits in APP/PSEN1 mice (by about 30\%, as we have previously reported [Koffie et al, 2009; Kay et al, 2013]), no such reduction of pre- or post-synaptic elements was detected in APP/ PSEN1/APOE ${ }^{\text {null }}$ mice. Still, the lack of APOE neither prevented the recruitment of $A \beta$ at the synapse and nor the decreased synaptic volume characteristic of amyloidosis mouse models. As the synaptic size is generally accepted as an indicator of connection strength (Kasai et al, 2010; Penzes et al, 2011), it is possible that synaptic stability remains compromised in APP/PSEN1/APOE ${ }^{\text {null }}$ mice. In addition, we have previously reported that the different APOE isoforms differentially modulate the recruitment of $A \beta$ at the synapse in human AD brains (Koffie et al, 2012), therefore acting as a chaperone toward neurotoxic amyloid peptides. The fact that $A \beta$ still co-localizes with synaptic terminals in the absence of APOE implies that other factors may be involved to shuttle those neurotoxic species at the synapse. Among others, apolipoprotein J (Apo), or clusterin) is a likely candidate, as it is also known to interact with $A \beta$ and modify its aggregation and deposition (Mulder et al, 2014; Miners et al, 2017). Whether or not this is the case remains to be determined, as we did observe a rescue of neuronal function in the absence of APOE alone, therefore indicating that the presence of $A \beta$ at the synapse is necessary but not sufficient to trigger synaptic collapse. Because our findings place APOE as a pivotal factor triggering amyloid synaptotoxicity, it is possible that its association with $A \beta$ is necessary for it to adopt a toxic conformation or allows the interaction between $A \beta$ and specific cellular receptors 
(such as APP itself, as recently reported [Wang et al, 2017], TREM2 [Yeh et al, 2016], or any other APOE receptors [Holtzman et al, 2012; Lane-Donovan \& Herz, 2017]) to initiate various deleterious molecular cascades in neurons or even in glial cells.

\section{Materials and Methods}

\section{Animals}

APPswe/PS1dE9 (APP/PSEN1) mice (The Jackson Laboratory [Jankowsky et al, 2004; Reiserer et al, 2007]) were used for the study. This mouse model expresses the human mutant APP and presenilin genes respectively containing the Swedish mutation K594N/M595L and the exon 9 deletion. Amyloid deposition starts as early as 3-mo old in this model, with most amyloid plaques being of fibrillar nature because of the presence of the $\triangle E 9$ PS1 mutation leading to an increase in $A \beta 42 / 40$ ratio. To generate APP/PSEN1/APOE ${ }^{\text {null }}$ mice, one APP/PSEN1 hemizygous transgenic animal was crossed with an APOE ${ }^{\text {null }}$ breeder (The Jackson Laboratory). The resulting APP/PSEN1/APOE ${ }^{+/-}$offspring was then crossed with another $A P O E^{\text {null }}$ breeder to generate APP/PSEN1/APOE ${ }^{\text {null }}$ and $A P O E^{\text {null }}$ animals. The resulting APP/PSEN1/APOE ${ }^{\text {null }}$ offspring was then bred with $\mathrm{APOE}^{\text {null }}$ mice to generate all the animals used in this study. Controls included littermates from the APP/PSEN1 colony altogether with C57BL/ 6 (appropriate controls of the APOE ${ }^{\text {null }}$ mice). We had previously verified that these control groups showed similar responses to visual stimulation and, therefore, could be merged together. Genotyping for APOE and APP were performed by PCR following the protocol given by The Jackson's Laboratory. A detailed description of the cohort is presented in Fig S1. All animal experiments were approved by the Massachusetts General Hospital Subcommittee on Research Animal Care following the guidelines set forth by the National Institutes of Health Guide for the Care and Use of Laboratory Animals.

\section{Viral vector construction and production}

The yellow cameleon CDNA (YC3.6) was cloned to an AAV2 backbone, under a hybrid CMV immediate-early enhancer/chicken $\beta$-actin promoter/exon1/intron and before the woodchuck hepatitis virus posttranscriptional regulatory element (WPRE). High titers of AAV serotype 8 were produced using a conventional triple transfection approach by the PENN Vector Core (University of Pennsylvania). Viruses were tittered by quantitative PCR, and the final concentrations of the AAV viral stocks used for this study reached $4 \times 10^{12}$ $\mathrm{vg} / \mathrm{ml}$.

\section{Intracortical AAV injection and cranial window implantation}

Surgical procedures were performed as described previously (Hudry et al, 2010; Kuchibhotla et al, 2014; Arbel-Ornath et al, 2017), with minor modifications. Mice were anesthetized by intraperitoneal injection of ketamine/xylazine $(100 \mathrm{mg} / \mathrm{kg}$ and 50 $\mathrm{mg} / \mathrm{kg}$, respectively, body weight) and positioned on a stereotactic frame (Kopf Instruments). A 3-mm cranial window was opened above the right primary visual cortex V1 (coordinates from $\lambda$ : $+0.5 \mathrm{~mm}$ anteroposterior, $2.7 \mathrm{~mm}$ lateral, and $0.6 \mathrm{~mm}$ dorsoventral). After removing the skull, $3 \mu \mathrm{l}\left(1.2 \times 10^{10} \mathrm{vg}\right)$ of AAV8-CBAYC3.6 viral suspension was injected at a rate of $0.15 \mu \mathrm{l} /$ minute in the layer $2 / 3$ neurons using a 33-gauge sharp needle attached to a $10-\mu l$ Hamilton syringe (Hamilton Medical). The window was then closed with a 5-mm-diameter cover glass and secured with a mixture of dental cement and Krazy Glue. A custom-made stainless steel headpost (Ponoko) was finally fixed to the skull using $C \& B$ Metabond dental cement (Parkell) to allow recording in awake mice. After a recovery period of one month, the mice were habituated to the head-fixation device (Thorlabs posts and Altos head clamps) by running freely on a circular treadmill (Ponoko) for $15 \mathrm{~min}$ a week before the first imaging.

\section{Recording of visually evoked neuronal responses}

For in vivo calcium imaging, an Olympus FluoView FV1000MPE multiphoton laser scanning system mounted on an Olympus BX61WI microscope and an Olympus 25× dipping objective (NA = 1.05 , Olympus) were used, with the emission path shielded from external light contamination. A DeepSee Mai Tai Ti:sapphire modelocked laser (Mai Tai; Spectra-Physics) generated two-photon excitation at $860 \mathrm{~nm}$, and detectors containing three photomultiplier tubes (Hamamatsu) collected emitted light in the range of 460-500, 520-560, and 575-630 nm. CFP and YFP photomultipliers (PMTs) settings remained unchanged throughout the different imaging sessions, but laser power was adjusted as needed. The mice were imaged awake and directly placed under the objective. To detect visually evoked neuronal responses, time courses of calcium transients were recorded in head-fixed awake animals while a 19-inch LCD monitor (Viewsonic VP930B) displayed the visual stimuli in front of the left eye (screen-eye distance, $20 \mathrm{~cm}$; screen-midline angle, $60^{\circ}$ ). Visual stimuli were drifting $(2 \mathrm{~Hz}$ ) sine-wave gratings ( 80 or $100 \%$ contrast, black and white) presented for $7 \mathrm{~s}$. Eight stimuli (at $45^{\circ}$ orientation increments) were presented sequentially in counterclockwise order with a 7-s pause between stimuli, and 10 cycles of visual stimulation were presented during each recording. For each imaging session, two to three cortical frames $(254 \mu \mathrm{m} \times 254 \mu \mathrm{m}$, scan rate $2.3 \mathrm{~Hz}, 0.429 \mathrm{~s} /$ frame, depth of 200-300 $\mu \mathrm{m}$ ) were taken.

\section{Image processing and analysis}

In vivo imaging data were analyzed using custom-written scripts in Fiji (National Institutes of Health: http://fiji.sc/) and MATLAB (MathWorks). Images were aligned for shifts in the $x-y$ plane using the StackReg function of Fiji, neuronal cell bodies (identified by the presence of neuritic processes) were manually selected (ROIs), YFP: CFP ratios were created and spatially filtered, and raw time courses were extracted. "Responsive" cells were detected by comparing the change in directional response ( $\triangle \mathrm{R} ; \mathrm{R}$ - Rnonstimulated) across directions and against background, and $(P<0.05$, ANOVA with the Tukey-Cramer post hoc test and Bonferonni correction). Only responsive cells were used for further analysis of orientation and direction tuning. The OSI and DSI were calculated as described previously (Kuchibhotla et al, 2014). In short, OSI was calculated as the maximum directional response, $\triangle \mathrm{Rmax}$, and divided by the sum 
of responses in all other directions, $\Sigma \Delta$ Rother $(0 \leq \mathrm{OSI} \leq 1 ; 1=$ perfectly orientation-tuned). DSI was calculated as $\Delta$ Rmax divided by the sum of that direction and the antiparallel direction, $\Delta$ Rmaxr+ $\Delta$ Rorthogonal ( $0 \leq \mathrm{DSI} \leq 1 ; 1=$ perfectly direction-tuned). The higher the values for OSI and DSI, the better the neuron tuned to a specific visual stimulus.

\section{Tissue collection and processing}

Mice were euthanized by $\mathrm{CO}_{2}$ asphyxiation and tissue collected for immunohistochemical and biochemical analysis. For the mice that underwent in vivo imaging, the right hemisphere (containing the surgical site) was fixed by immersion in $4 \%$ paraformaldehyde and $15 \%$ glycerol in PBS for $48 \mathrm{~h}$ before cryoprotection with $30 \%$ glycerol in PBS. A few $1-\mathrm{mm}^{3}$ pieces of tissue were cut across the left hemisphere for array tomography. Because the surgical procedure and the injection of AAV-CBA-YC could have compromised the results of our stereological analyses, another cohort of APP/PSEN1 and APP/PSEN1/APOE ${ }^{\text {null }}$ mice was used to perform the stereological work (right hemisphere) and the isolation of synaptoneurosomes (from the left hemisphere directly snap-frozen in liquid nitrogen and stored at $-80^{\circ} \mathrm{C}$ ). Additional mice were euthanized to perform the sequential brain extraction from cortices.

\section{Synaptoneurosomes preparation and Western blotting}

Synaptoneurosome preparations were based on procedures described by Tai et al (2012) with minor modifications. Briefly, an entire mouse hemisphere (about $250 \mathrm{mg}$ of frozen tissue, without cerebellum and olfactory bulbs) was homogenized in 1.2- $\mathrm{ml}$ cold Buffer A (25 mM Tris, pH 7.5, $120 \mathrm{mM} \mathrm{NaCl}, 5 \mathrm{mM} \mathrm{KCl}, 1 \mathrm{mM} \mathrm{MgCl}, 2 \mathrm{mM} \mathrm{CaCl}$, $1 \mathrm{mM}$ dithiothreitol, and Complete protease inhibitors; Roche), before being filtered through $80-\mu \mathrm{m}$ nylon filters (Millipore). An aliquot of the filtrate was supplemented with SDS to 1\%, boiled for 5 min, and centrifuged at 15,000 $\mathrm{g}$ for $15 \mathrm{~min}$, and the supernatant was collected as total extract. The other portion was further filtered through 5- $\mu \mathrm{m}$ pore filters (PALL Acrodisc) and centrifuged at $1,000 \mathrm{~g}$ for $10 \mathrm{~min}$ at $4^{\circ} \mathrm{C}$ to pellet synaptoneurosomes. The supernatant, corresponding to the cytosolic extract, was further centrifuged at $100,000 \mathrm{~g}$ for $20 \mathrm{~min}$ to remove microsomes or other extracellular vesicles. The synaptoneurosome pellet was washed once with cold Buffer $A$ and centrifuged again at 1,000 $\mathrm{g}$ for $10 \mathrm{~min}$. The pellet was extracted with $0.5 \mathrm{ml}$ Buffer B (50 mM Tris, pH 7.5, 1\% SDS, and 2 mM dithiothreitol) and boiled for $5 \mathrm{~min}$. After centrifugation at 15,000 $\mathrm{g}$ for $15 \mathrm{~min}$, the supernatant was collected as synaptoneurosomal extract. Protein content was measured by BCA assay (Pierce). The protein concentration was adjusted to $10 \mu \mathrm{g} / 10 \mu \mathrm{l}$ for all Western blot samples, including Laemmli blue buffer and reducing agent. The samples were electrophoresed on $4-12 \%$ Bis-Tris gels in MES running buffer (Invitrogen). After transferring on nitrocellulose membrane (GE Healthcare), the blots were blocked for $1 \mathrm{~h}$ at RT in Odyssey Blocking Buffer (Li-Cor), before probing the membranes overnight at $4^{\circ} \mathrm{C}$ with the primary antibodies diluted in blocking buffer (1:1,000, Table 1). Incubation with IRDye $800 \mathrm{CW}$ or IRDye $680 \mathrm{CW}$ secondary antibodies (Li-Cor) followed $(1: 2,000)$ before detection of the near infrared signals using an Odissey CLx imager system (Li-Cor). Signal intensity was measured by densitometry using the Integrated Density function of Fiji software (http:/ / fiji.sc/) and divided to GAPDH signal intensity. The samples from each batch of SNS were first normalized to the signal observed in the controls (Littermates), before performing statistical analyses on all SNS preparations.

\section{Sequential brain extraction}

Sequential brain extraction was performed as described previously (Hashimoto et al, 2012) from one cerebral hemisphere, after dissection of the olfactory bulb and cerebellum. The tissue was initially homogenized in 10 volumes of TBSI (Tris-buffered saline with protease inhibitor cocktail; Roche) with 25 strokes on a mechanical Dounce homogenizer and centrifuged at $100,000 \mathrm{~g}$ for $30 \mathrm{~min}$ at $4^{\circ} \mathrm{C}$. The supernatant was collected as TBS-soluble fraction. The resulting pellet was consecutively extracted with TBS buffers containing $2 \%$ Triton and 2\% SDS (with protease inhibitors), alternating homogenization and ultracentrifugation steps (100,000 $\mathrm{g}$ for $30 \mathrm{~min})$. The final pellet was solubilized in $500 \mu \mathrm{l}$ of FA by sonication. After a final ultracentrifugation step, the FA-soluble fraction was desiccated and the pellet resuspended in $100 \mu \mathrm{l}$ of DMSO. The content in the most soluble (TBS) and insoluble (FA) A $\beta$ species was analyzed in this study. The concentrations of $A \beta 40, A \beta 42$, and $A \beta$ oligomers were respectively quantified with a mouse/human ELISA kit (Wako) and a human Amyloid $\beta$ oligomers (82E1-specific) assay (IBL international).

\section{Immunohistology}

After cryoprotection of the brain in $30 \%$ glycerol for $48 \mathrm{~h}, 40-\mu \mathrm{m}$-thick floating sections were cut on a freezing microtome in the sagittal plane. Floating sections were successfully permeabilized in $0.5 \%$ Triton in TBS for 30 min, blocked in 5\% normal goat serum in TBS for 1 $h$, and incubated with primary antibody overnight at $4^{\circ} \mathrm{C}$ in $2.5 \%$ NGS and $0.1 \%$ Triton in TBS (see Table 1 for a complete list of primary antibodies used). The sections were then washed with TBS and incubated with appropriate Alexa-Fluor 488- or Alexa-Fluor 568conjugated secondary antibodies diluted in 2.5\% NGS and $0.1 \%$ TritonX in TBS. After another round of washing, the sections were mounted onto slides and coverslipped with VECTASHIELD Mounting Medium with DAPI (Vector Labs). For the counterstaining of amyloid with Methoxy- $\mathrm{XO}_{4}$, the floating sections were incubated for $15 \mathrm{~min}$ in a solution of $1 \mu \mathrm{g} / \mathrm{ml}$ of Methoxy- $\mathrm{XO}_{4}$ (diluted in TBS) before mounting the slices with Fluoromount-G (No DAPI, SouthernBiotech).

\section{Stereology-based quantitative analyses}

All pathology quantification was carried out blinded until the last statistical analyses. Stereology-based studies of amyloidassociated neuritic dystrophies, reactive astrocytes, and microglia were performed on immunolabeled sections using an Olympus BX52 epifluorescent microscope equipped with motorized stage, DP70 digital CCD camera, and CAST stereology software (Olympus). The cortex was outlined under low-power objective $(4 \times)$, and dystrophies, astrocytes, and microglia counts were made using $20 \times$ high numerical aperture (1.2) objective. Using a meander sampling of $70 \%$ of cortical area, images were captured each time an amyloid deposit was encountered. Those images were then analyzed using 
Table 1. List of antibodies used for the study.

\begin{tabular}{|c|c|c|c|c|}
\hline Antigen & Species & Polyclonal/Monoclonal & Manufacturer & Cat. No \\
\hline \multicolumn{5}{|c|}{ Antibodies used for Immunohistology (IH)/WB } \\
\hline$A \beta(N$-terminal) & Rabbit & Polyclonal & IBL/Tecan & 18584 \\
\hline A $\beta$ 1-12 (clone BAM10) & Mouse & Monoclonal & Sigma-Aldrich & A3981 \\
\hline Iba1 & Rabbit & Polyclonal & Wako & 019-19741 \\
\hline GFAP & Mouse & Monoclonal & Sigma-Aldrich & G3893 \\
\hline Neurofilament (SMI-311R) & Mouse & Monoclonal, IgM, IgG1 & BioLegend & 837801 \\
\hline GABA B receptor 1 & Mouse & Monoclonal, IgG 2a & Abcam & ab55051 \\
\hline NMDAR 1 & Rabbit & Monoclonal & Abcam & ab109182 \\
\hline NMDAR2B & Rabbit & Polyclonal & Abcam & ab65783 \\
\hline NMDAR2A & Rabbit & Monocloncal, IgG & Millipore & 04-901 \\
\hline GABA A receptor $\alpha 1$ & Rabbit & Polyclonal & Abcam & ab33299 \\
\hline PSD95 & Rabbit & Monoclonal & Cell Signaling & $3450 S$ \\
\hline GAPDH & Mouse & Monoclonal & Abcam & ab9484 \\
\hline Actin & Mouse & Monoclonal & Sigma-Aldrich & A4700 \\
\hline \multicolumn{5}{|c|}{ Antibodies used for array tomography } \\
\hline Oligomeric $A \beta(1 C 22)$ & Mouse & Monoclonal & Dr. Walsh's lab & Yang, O'Malley et al (2015) \\
\hline Synapsin 1 & Rabbit & Polyclonal & Millipore & AB1543P \\
\hline PSD95 & Guinea-pig & Polyclonal & Synaptic Systems & 124014 \\
\hline
\end{tabular}

Fiji, counting the number of GFAP-positive astrocytes, Iba1-positive microglial cells or neuritic dystrophies (visible after immunostaining for neurofilaments) close to a plaque $(<50 \mu \mathrm{m})$ and reporting this number to the surface of the plaque considered. For the quantification of amyloid load and amyloid density, Alexa-568anti-Amyloid and Methoxy-X04-positive plaques were imaged using a NanoZoomer-XR digital slide scanner (Hamamatsu) under a $\times 20$ objective. After conversion of the.$n d p i s$ files to tiff format, the number of deposits and their surface were determined using a custom-written script based on the "Analyze particle" function of Fiji (National Institutes of Health: http://fiji.sc/). The total surface occupied by amyloid and the total number of plaques were then reported to the cortical area of each section considered.

\section{Array tomography}

\section{Sample collection and tissue processing}

Array tomography analyses were performed as previously described (Hudry et al, 2013; Kay et al, 2013). Five to six pieces of cortical tissue $\left(1 \mathrm{~mm}^{3}\right)$ were dissected and fixed for $3 \mathrm{~h}$ in $4 \%$ paraformaldehyde and $2.5 \%$ sucrose in $0.01 \mathrm{M}$ PBS. After dehydration in ethanol, the samples were incubated in LR White resin (Electron Microscopy Sciences) overnight at $4^{\circ} \mathrm{C}$ before polymerization at $53^{\circ} \mathrm{C}$. Ribbons of $20-40$ ultrathin (70 nm thick) serial sections were cut with a Histo Jumbo diamond knife (Diatome) on an ultracut microtome (Leica) and mounted on glass coverslips.

\section{Staining and imaging}

Ribbons were incubated in glycine (50 mM glycine in 1× TBS) for 5 min and blocked in blocking solution (0.05\% Tween and 0.1\% fish gelatin [Sigma-Aldrich] in $1 \times$ TBS) for $1 \mathrm{~h}$ before antibody staining. All antibodies (summarized in Table 1) were spun for $4 \mathrm{~min}$ at $10,000 \mathrm{~g}$ before being applied. Mouse $1 \mathrm{C} 22$ against oligomeric $A \beta$ (1:200, donated by Dominic Walsh [Yang et al, 2015], rabbit antisynapsin-1 (1:50, Rb X Synapsin I, AB1543P; Millipore) and guinea pig anti-PSD95 (1:50, Anti-PSD95, 124014; Synaptic Systems [Koffie et al, 2009]) primary antibodies in block solution were added and incubated at $4^{\circ} \mathrm{C}$ overnight. Incubation with secondary antibodies diluted 1:50 in block solution (Alexa FluorTM 488 donkey anti-mouse IgG $[\mathrm{H}+\mathrm{L}]$, Invitrogen; Alexa FluorTM 594 donkey anti-rabbit IgG $[\mathrm{H}+$ L], Invitrogen; and Alexa FluorTM 647 goat anti-guinea pig IgG [H+L], Invitrogen) was performed for $1 \mathrm{~h}$ at room temperature, before counterstaining with DAPI for $5 \mathrm{~min}$. Shandon Immu-Mount (Thermo Fisher Scientific) solution was used to mount the slides on polysine microscope slides (VWR International). Serial sections of the ribbon were imaged with a Zeiss Axiolmager Z2 epifluorescent microscope, first at $10 \times$ to obtain a tilescan of the entire ribbon, then with a $63 \times 1.4$ NA Plan Apochromat objective for highresolution images. Images were acquired with a Coolsnap digital camera and Axiolmager software with array tomography macros (Carl Zeiss, Ltd). In short, two distinct areas were selected on each $10 \times$ tilescan. Once the areas were selected on two serial slices of the ribbon, the Axiolmager software was able to find the same areas in each one of the subsequent slices and image them at 63x.

\section{Data analyses}

Image stacks were aligned using Image) (National Institutes of Health open software; multistackreg macro [Thevenaz et al, 1998]). ROI $(10 \mu \mathrm{m} \times 10 \mu \mathrm{m})$ were cropped on the stack near plaques $(<10 \mu \mathrm{m}$ from the plaque edge) and far away from plaques ( $>35 \mu \mathrm{m}$ from the edge of the halo). When no plaques were present (in wild-type and APOE ${ }^{\text {null }}$ 
mice), ROI were randomly selected on the stack. Custom algorithms were used to threshold the crops in IMAGEJ/FIJI (Schindelin et al, 2012). Custom MATLAB macros were used to remove puncta that were only found in a single section, detect synapses, quantify the numbers and sizes of synaptic puncta, and determine which synaptic puncta were co-localized with $A \beta$. Synaptic density was calculated as the number of puncta per volume of tissue sampled (synapses $/ \mathrm{mm}^{3}$ ).

\section{Statistical analyses}

A detailed summary of the statistical analyses performed is presented in the Supplemental Information 1 "Statistical analyses," including the test chosen for each analysis, exact $P$-values and confidence intervals. The statistical software SAS was used to analyze the relationship between adjusted DSI/OSI and genotype, age, and the interaction between them. A linear mixed model was fitted to the DSI and OSI values after log transformation, with these factors (genotype or age) as fixed effects and mouse as random effect. Significance was set for $P$-values $<0.05$.

Array tomography data were analyzed using GraphPad Prism software, and $P<0.05$ was considered significant. Shapiro-Wilk test was used to check for normal distribution of data. Brown-Forsythe test (with ANOVA or the nonparametric equivalent Kruskal-Wallis test) and F-test (with $t$ test or the nonparametric equivalent Mann-Whitney test) were used to check for equality of variance of the data. Synaptic density in crops was measured and averaged for each mouse. A two-way ANOVA test followed by a Tukey's multiple comparisons post hoc test was used to compare synaptic density using distance from plaques and mouse genotype as the two variables. A t test was used to compare the percentage of $1 \mathrm{C} 22 \mathrm{CO}-$ localizing at synapses close to plaques in APP and APP/APOE ${ }^{\text {null }}$ mice. One-way ANOVA test (or the nonparametric equivalent Kruskal-Wallis test) followed by a Holm Sidak's or a Tukey's multiple comparisons post hoc tests and test (or the nonparametric equivalent Mann-Whitney test) were used to compare synaptic volume across genotypes far and close from plaques.

All the other results (stereology, Western blotting) were analyzed using GraphPad software. Normality was initially validated using the D'Agostino and Pearson omnibus normality test. Difference between each group was tested using a one-way ANOVA (in case of normality) or a Kruskal-Wallis test (non-normal distribution) followed by with post hoc Dunn's multiple comparison test. In case of comparisons between two groups only (APP/PSEN1 and APP/PSEN1/APOE ${ }^{\text {null }}$ ), a conventional $t$ test (normality) or a Mann-Whitney test (non-normal distribution) was performed. Data are presented as mean \pm SD.

\section{Supplementary Information}

Supplementary Information is available at https://doi.org/10.26508/lsa. 201900325.

\section{Acknowledgements}

This work was supported by the National Institute of Health/the National Institute on Aging 1K99AG047336-01A1 (E Hudry) and 5R01AG047644-04
(BT Hyman). T Spires-Jones, R Jackson, and C Cannavo are supported by the UK Dementia Research Institute, European Research Council, Alzheimer's Research UK (ARUK-SPG2013-1), Wellcome Trust-University of Edinburgh Institutional Strategic Support Fund, and Alzheimer's Society (AS-PG-15b023). T Spires-Jones is a member of the Federation of European Neuroscience Kavli Network of Excellence.

\section{Author Contributions}

E Hudry: conceptualization, resources, data curation, formal analysis, supervision, funding acquisition, validation, investigation, visualization, methodology, project administration, and writing-original draft, review, and editing.

J Klickstein: data curation, formal analysis, and writing-review and editing.

C Cannavo: data curation, formal analysis, and writing-original draft, review, and editing.

R Jackson: data curation, formal analysis, methodology, and writing-original draft, review, and editing.

A Muzikansky: formal analysis, methodology, and writing-original draft, review, and editing.

S Gandhi: data curation, formal analysis, and methodology.

D Urick: data curation and formal analysis.

T Sargent: data curation and formal analysis.

L Wrobleski: data curation and formal analysis.

AD Roe: data curation, formal analysis, and project administration. SS Hou: formal analysis and methodology.

KV Kuchibhotla: supervision, methodology, and writing-original draft, review, and editing.

RA Betensky: formal analysis, supervision, methodology, and writing-original draft, review, and editing.

T Spires-Jones: conceptualization, supervision, funding acquisition, methodology, and writing-original draft, review, and editing.

BT Hyman: conceptualization, formal analysis, supervision, funding acquisition, and writing-original draft, review, and editing.

\section{Conflict of Interest Statement}

The authors declare that they have no conflict of interest.

\section{References}

Andermann ML, Kerlin AM, Roumis DK, Glickfeld LL, Reid RC (2011) Functional specialization of mouse higher visual cortical areas. Neuron 72: 1025-1039. doi:10.1016/j.neuron.2011.11.013

Arbel-Ornath M, Hudry E, Boivin JR, Hashimoto T, Takeda S, Kuchibhotla KV, Hou S, Lattarulo CR, Belcher AM, Shakerdge N, et al (2017) Soluble oligomeric amyloid-beta induces calcium dyshomeostasis that precedes synapse loss in the living mouse brain. Mol Neurodegener 12: 27. doi:10.1186/s13024-017-0169-9

Atagi Y, Liu CC, Painter MM, Chen XF, Verbeeck C, Zheng H, Li X, Rademakers R, Kang SS, Xu H, et al (2015) Apolipoprotein E is a ligand for triggering receptor expressed on myeloid cells 2 (TREM2). J Biol Chem 290: 26043-26050. doi:10.1074/jbc.m115.679043

Bales KR, Verina T, Dodel RC, Du Y, Altstiel L, Bender M, Hyslop P, Johnstone EM, Little SP, Cummins DJ, et al (1997) Lack of apolipoprotein E dramatically reduces amyloid beta-peptide deposition. Nat Genet 17: 263-264. doi:10.1038/ng1197-263 
Bien-Ly N, Gillespie AK, Walker D, Yoon SY, Huang Y (2012) Reducing human apolipoprotein E levels attenuates age-dependent Abeta accumulation in mutant human amyloid precursor protein transgenic mice. J Neurosci 32: 4803-4811. doi:10.1523/jneurosci.0033-12.2012

Bjorkhem I, Meaney S (2004) Brain cholesterol: Long secret life behind a barrier. Arterioscler Thromb Vasc Biol 24: 806-815. doi:10.1161/01. ATV.0000120374.59826.1b

Bour A, Grootendorst J, Vogel E, Kelche C, Dodart JC, Bales K, Moreau PH, Sullivan PM, Mathis C (2008) Middle-aged human apoE4 targetedreplacement mice show retention deficits on a wide range of spatial memory tasks. Behav Brain Res 193: 174-182. doi:10.1016/j. bbr.2008.05.008

Boyles JK, Pitas RE, Wilson E, Mahley RW, Taylor JM (1985) Apolipoprotein E associated with astrocytic glia of the central nervous system and with nonmyelinating glia of the peripheral nervous system. J Clin Invest 76: 1501-1513. doi:10.1172/jci112130

Bublak P, Redel P, Sorg C, Kurz A, Forstl H, Muller HJ, Schneider WX, Finke K (2011) Staged decline of visual processing capacity in mild cognitive impairment and Alzheimer's disease. Neurobiol Aging 32: 1219-1230. doi:10.1016/j.neurobiolaging.2009.07.012

Cantuti-Castelvetri L, Fitzner D, Bosch-Queralt M, Weil MT, Su M, Sen P, Ruhwedel T, Mitkovski M, Trendelenburg G, Lutjohann D, et al (2018) Defective cholesterol clearance limits remyelination in the aged central nervous system. Science 359: 684-688. doi:10.1126/science. aan4183

Castellano JM, Kim J, Stewart FR, Jiang H, DeMattos RB, Patterson BW, Fagan AM, Morris JC, Mawuenyega KG, Cruchaga C, et al (2011) Human apoE isoforms differentially regulate brain amyloid-beta peptide clearance. Sci Transl Med 3: 89ra57. doi:10.1126/scitranslmed.3002156

Chen Y, Li B, Zhao RR, Zhang HF, Zhen C, Guo L (2015) Increased sensitivity of apolipoprotein $\mathrm{E}$ knockout mice to copper-induced oxidative injury to the liver. Biochem Biophys Res Commun 459: 529-533. doi:10.1016/j. bbrc.2015.02.143

Corder EH, Saunders AM, Risch NJ, Strittmatter WJ, Schmechel DE, Gaskell PC Jr, Rimmler JB, Locke PA, Conneally PM, Schmader KE, et al (1994) Protective effect of apolipoprotein E type 2 allele for late onset Alzheimer disease. Nat Genet 7: 180-184. doi:10.1038/ng0694-180

Corder EH, Saunders AM, Strittmatter WJ, Schmechel DE, Gaskell PC, Small GW, Roses AD, Haines JL, Pericak-Vance MA (1993) Gene dose of apolipoprotein E type 4 allele and the risk of Alzheimer's disease in late onset families. Science 261: 921-923. doi:10.1126/science.8346443

Cronin-Golomb A, Corkin S, Rizzo JF, Cohen J, Growdon JH, Banks KS (1991) Visual dysfunction in Alzheimer's disease: Relation to normal aging. Ann Neurol 29: 41-52. doi:10.1002/ana.410290110

Cullum CM, Weiner MF (2015) Apolipoprotein E and neurocognitive function. JAMA Neurol 72: 478. doi:10.1001/jamaneurol.2014.4702

Deane R, Sagare A, Hamm K, Parisi M, Lane S, Finn MB, Holtzman DM, Zlokovic BV (2008) apoE isoform-specific disruption of amyloid beta peptide clearance from mouse brain. J Clin Invest 118: 4002-4013. doi:10.1172/ jci36663

Dickson DW (1997) The pathogenesis of senile plaques. J Neuropathol Exp Neurol 56: 321-339. doi:10.1097/00005072-199704000-00001

Evola M, Hall A, Wall T, Young A, Grammas P (2010) Oxidative stress impairs learning and memory in apoE knockout mice. Pharmacol Biochem Behav 96: 181-186. doi:10.1016/j.pbb.2010.05.003

Fagan AM, Watson M, Parsadanian M, Bales KR, Paul SM, Holtzman DM (2002) Human and murine ApoE markedly alters A beta metabolism before and after plaque formation in a mouse model of Alzheimer's disease. Neurobiol Dis 9: 305-318. doi:10.1006/nbdi.2002.0483

Fullerton SM, Shirman GA, Strittmatter WJ, Matthew WD (2001) Impairment of the blood-nerve and blood-brain barriers in apolipoprotein e knockout mice. Exp Neurol 169: 13-22. doi:10.1006/exnr.2001.7631
Garai K, Verghese PB, Baban B, Holtzman DM, Frieden C (2014) The binding of apolipoprotein $\mathrm{E}$ to oligomers and fibrils of amyloid-beta alters the kinetics of amyloid aggregation. Biochemistry 53: 6323-6331. doi:10.1021/bi5008172

Gordon I, Grauer E, Genis I, Sehayek E, Michaelson DM (1995) Memory deficits and cholinergic impairments in apolipoprotein E-deficient mice. Neurosci Lett 199: 1-4. doi:10.1016/0304-3940(95)12006-p

Grienberger C, Rochefort NL, Adelsberger H, Henning HA, Hill DN, Reichwald J, Staufenbiel M, Konnerth A (2012) Staged decline of neuronal function in vivo in an animal model of Alzheimer's disease. Nat Commun 3: 774. doi:10.1038/ncomms1783

Hafezi-Moghadam A, Thomas KL, Wagner DD (2007) ApoE deficiency leads to a progressive age-dependent blood-brain barrier leakage. Am J Physiol Cell Physiol 292: C1256-C1262. doi:10.1152/ajpcell.00563.2005

Hartman RE, Wozniak DF, Nardi A, Olney JW, Sartorius L, Holtzman DM (2001) Behavioral phenotyping of GFAP-apoE3 and -apoE4 transgenic mice: apoE4 mice show profound working memory impairments in the absence of Alzheimer's-like neuropathology. Exp Neurol 170: 326-344. doi:10.1006/exnr.2001.7715

Hashimoto T, Serrano-Pozo A, Hori Y, Adams KW, Takeda S, Banerji AO, Mitani A, Joyner D, Thyssen DH, Bacskai BJ, et al (2012) Apolipoprotein E, especially apolipoprotein $\mathrm{E} 4$, increases the oligomerization of amyloid beta peptide. J Neurosci 32: 15181-15192. doi:10.1523/jneurosci.1542-12.2012

Holtzman DM, Bales KR, Tenkova T, Fagan AM, Parsadanian M, Sartorius LJ, Mackey B, Olney J, McKeel D, Wozniak D, et al (2000) Apolipoprotein E isoform-dependent amyloid deposition and neuritic degeneration in a mouse model of Alzheimer's disease. Proc Natl Acad Sci U S A 97: 2892-2897. doi:10.1073/pnas.050004797

Holtzman DM, Fagan AM (1998) Potential role of apoE in structural plasticity in the nervous system; implications for disorders of the central nervous system. Trends Cardiovasc Med 8: 250-255. doi:10.1016/s10501738(98)00017-6

Holtzman DM, Herz J, Bu G (2012) Apolipoprotein E and apolipoprotein E receptors: Normal biology and roles in Alzheimer disease. Cold Spring Harb Perspect Med 2: a006312. doi:10.1101/cshperspect.a006312

Hong S, Beja-Glasser VF, Nfonoyim BM, Frouin A, Li S, Ramakrishnan S, Merry KM, Shi Q, Rosenthal A, Barres BA, et al (2016) Complement and microglia mediate early synapse loss in Alzheimer mouse models. Science 352: 712-716. doi:10.1126/science.aad8373

Hori $\mathrm{Y}$, Hashimoto T, Nomoto H, Hyman BT, Iwatsubo T (2015) Role of apolipoprotein $\mathrm{E}$ in beta-amyloidogenesis: Isoform-specific effects on protofibril to fibril conversion of Abeta in vitro and brain Abeta deposition in vivo. J Biol Chem 290: 15163-15174. doi:10.1074/jbc. m114.622209

Huang Y, Mahley RW (2014) Apolipoprotein E: Structure and function in lipid metabolism, neurobiology, and Alzheimer's diseases. Neurobiol Dis 72 Pt A: 3-12. doi:10.1016/j.nbd.2014.08.025

Hudry E, Dashkoff J, Roe AD, Takeda S, Koffie RM, Hashimoto T, Scheel M, Spires-Jones T, Arbel-Ornath M, Betensky R, et al (2013) Gene transfer of human Apoe isoforms results in differential modulation of amyloid deposition and neurotoxicity in mouse brain. Sci Transl Med 5: 212ra161. doi:10.1126/scitranslmed.3007000

Hudry E, Van Dam D, Kulik W, De Deyn PP, Stet FS, Ahouansou O, Benraiss A, Delacourte A, Bougneres P, Aubourg P, et al (2010) Adeno-associated virus gene therapy with cholesterol 24-hydroxylase reduces the amyloid pathology before or after the onset of amyloid plaques in mouse models of Alzheimer's disease. Mol Ther 18: 44-53. doi:10.1038/mt.2009.175

Huynh TV, Liao F, Francis CM, Robinson GO, Serrano JR, Jiang H, Roh J, Finn MB, Sullivan PM, Esparza TJ, et al (2017) Age-dependent effects of apoE reduction using antisense oligonucleotides in a model of betaamyloidosis. Neuron 96: 1013-1023 e4. doi:10.1016/j.neuron.2017.11.014

Hyman BT, Gomez-Isla T, Rebeck GW, Briggs M, Chung H, West HL, Greenberg S, Mui S, Nichols S, Wallace R, et al (1996) Epidemiological, clinical, 
and neuropathological study of apolipoprotein E genotype in Alzheimer's disease. Ann N Y Acad Sci 802: 1-5. doi:10.1111/j.17496632.1996.tb32592.x

Irizarry MC, Cheung BS, Rebeck GW, Paul SM, Bales KR, Hyman BT (2000a) Apolipoprotein E affects the amount, form, and anatomical distribution of amyloid beta-peptide deposition in homozygous APP (V717F) transgenic mice. Acta Neuropathol 100: 451-458. doi:10.1007/ s004010000263

Irizarry MC, Rebeck GW, Cheung B, Bales K, Paul SM, Holzman D, Hyman BT (2000b) Modulation of A beta deposition in APP transgenic mice by an apolipoprotein E null background. Ann N Y Acad Sci 920: 171-178.

Jankowsky JL, Fadale DJ, Anderson J, Xu GM, Gonzales V, Jenkins NA, Copeland NG, Lee MK, Younkin LH, Wagner SL, et al (2004) Mutant presenilins specifically elevate the levels of the 42 residue beta-amyloid peptide in vivo: Evidence for augmentation of a 42-specific gamma secretase. Hum Mol Genet 13: 159-170. doi:10.1093/hmg/ddh019

Jin JZ, Weng C, Yeh Cl, Gordon JA, Ruthazer ES, Stryker MP, Swadlow HA, Alonso JM (2008) On and off domains of geniculate afferents in cat primary visual cortex. Nat Neurosci 11: 88-94. doi:10.1038/nn2029

Kasai H, Fukuda M, Watanabe S, Hayashi-Takagi A, Noguchi J (2010) Structural dynamics of dendritic spines in memory and cognition. Trends Neurosci 33: 121-129. doi:10.1016/j.tins.2010.01.001

Kay KR, Smith C, Wright AK, Serrano-Pozo A, Pooler AM, Koffie R, Bastin ME, Bak TH, Abrahams S, Kopeikina KJ, et al (2013) Studying synapses in human brain with array tomography and electron microscopy. Nat Protoc 8 : 1366-1380. doi:10.1038/nprot.2013.078

Kitamura HW, Hamanaka H, Watanabe M, Wada K, Yamazaki C, Fujita SC, Manabe T, Nukina N (2004) Age-dependent enhancement of hippocampal long-term potentiation in knock-in mice expressing human apolipoprotein E4 instead of mouse apolipoprotein $\mathrm{E}$. Neurosci Lett 369: 173-178. doi:10.1016/j.neulet.2004.07.084

Knowles RB, Wyart C, Buldyrev SV, Cruz L, Urbanc B, Hasselmo ME, Stanley HE, Hyman BT (1999) Plaque-induced neurite abnormalities: Implications for disruption of neural networks in Alzheimer's disease. Proc Natl Acad Sci U S A 96: 5274-5279. doi:10.1073/pnas.96.9.5274

Koffie RM, Hashimoto T, Tai HC, Kay KR, Serrano-Pozo A, Joyner D, Hou S, Kopeikina KJ, Frosch MP, Lee VM, et al (2012) Apolipoprotein E4 effects in Alzheimer's disease are mediated by synaptotoxic oligomeric amyloid-beta. Brain 135: 2155-2168. doi:10.1093/brain/aws127

Koffie RM, Meyer-Luehmann M, Hashimoto T, Adams KW, Mielke ML, GarciaAlloza M, Micheva KD, Smith SJ, Kim ML, Lee VM, et al (2009) Oligomeric amyloid beta associates with postsynaptic densities and correlates with excitatory synapse loss near senile plaques. Proc Natl Acad Sci U S A 106: 4012-4017. doi:10.1073/pnas.0811698106

Koldamova R, Staufenbiel M, Lefterov I (2005) Lack of ABCA1 considerably decreases brain ApoE level and increases amyloid deposition in APP23 mice. J Biol Chem 280: 43224-43235. doi:10.1074/jbc.m504513200

Krasemann S, Madore C, Cialic R, Baufeld C, Calcagno N, El Fatimy R, Beckers L, O'Loughlin E, Xu Y, Fanek Z et al (2017) The TREM2-APOE pathway drives the transcriptional phenotype of dysfunctional microglia in neurodegenerative diseases. Immunity 47: 566-581 e9. doi:10.1016/j. immuni.2017.08.008

Kuchibhotla KV, Wegmann S, Kopeikina KJ, Hawkes J, Rudinskiy N, Andermann ML, Spires-Jones TL, Bacskai BJ, Hyman BT (2014) Neurofibrillary tangle-bearing neurons are functionally integrated in cortical circuits in vivo. Proc Natl Acad Sci U S A 111: 510-514. doi:10.1073/ pnas. 1318807111

Lane-Donovan C, Herz J (2017) ApoE, ApoE receptors, and the synapse in Alzheimer's disease. Trends Endocrinol Metab 28: 273-284. doi:10.1016/j.tem.2016.12.001

Lane-Donovan C, Wong WM, Durakoglugil MS, Wasser CR, Jiang S, Xian X, Herz J (2016) Genetic restoration of plasma ApoE improves cognition and partially restores synaptic defects in ApoE-deficient mice. I Neurosci 36: 10141-10150. doi:10.1523/jneurosci.1054-16.2016

Liang Z, Shen W, Sun C, Shou T (2008) Comparative study on the offset responses of simple cells and complex cells in the primary visual cortex of the cat. Neuroscience 156: 365-373. doi:10.1016/j. neuroscience.2008.07.046

Liao F, Hori Y, Hudry E, Bauer AQ, Jiang H, Mahan TE, Lefton KB, Zhang TJ, Dearborn JT, Kim J, et al (2014) Anti-ApoE antibody given after plaque onset decreases Abeta accumulation and improves brain function in a mouse model of Abeta amyloidosis. J Neurosci 34: 7281-7292. doi:10.1523/jneurosci.0646-14.2014

Liddelow SA, Guttenplan KA, Clarke LE, Bennett FC, Bohlen C), Schirmer L, Bennett ML, Munch AE, Chung WS, Peterson TC et al (2017) Neurotoxic reactive astrocytes are induced by activated microglia. Nature 541: 481-487. doi:10.1038/nature21029

Lippa CF, Smith TW, Saunders AM, Hulette C, Pulaski-Salo D, Roses AD (1997) Apolipoprotein E-epsilon 2 and Alzheimer's disease: Genotype influences pathologic phenotype. Neurology 48: 515-519. doi:10.1212/ wnl.48.2.515

Liu S, Breitbart A, Sun Y, Mehta PD, Boutajangout A, Scholtzova H, Wisniewski $\mathrm{T}$ (2014) Blocking the apolipoprotein E/amyloid beta interaction in triple transgenic mice ameliorates Alzheimer's disease related amyloid beta and tau pathology. J Neurochem 128: 577-591. doi:10.1111/ jnc.12484

Mahley RW (1988) Apolipoprotein E: Cholesterol transport protein with expanding role in cell biology. Science 240: 622-630. doi:10.1126/ science. 3283935

Mak AC, Pullinger CR, Tang LF, Wong JS, Deo RC, Schwarz JM, Gugliucci A, Movsesyan I, Ishida BY, Chu C et al (2014) Effects of the absence of apolipoprotein e on lipoproteins, neurocognitive function, and retinal function. JAMA Neurol 71: 1228-1236. doi:10.1001/jamaneurol.2014.2011

Masliah E, Samuel W, Veinbergs I, Mallory M, Mante M, Saitoh T (1997) Neurodegeneration and cognitive impairment in apoE-deficient mice is ameliorated by infusion of recombinant apoE. Brain Res 751: 307-314. doi:10.1016/s0006-8993(96)01420-5

Masliah E, Terry RD, Mallory M, Alford M, Hansen LA (1990) Diffuse plaques do not accentuate synapse loss in Alzheimer's disease. Am J Pathol 137: 1293-1297.

Mauch DH, Nagler K, Schumacher S, Goritz C, Muller EC, Otto A, Pfrieger FW (2001) CNS synaptogenesis promoted by glia-derived cholesterol. Science 294: 1354-1357. doi:10.1126/science.294.5545.1354

Miners JS, Clarke P, Love S (2017) Clusterin levels are increased in Alzheimer's disease and influence the regional distribution of Abeta. Brain Pathol 27: 305-313. doi:10.1111/bpa.12392

Mulder SD, Nielsen HM, Blankenstein MA, Eikelenboom P, Veerhuis R (2014) Apolipoproteins $\mathrm{E}$ and $\mathrm{J}$ interfere with amyloid-beta uptake by primary human astrocytes and microglia in vitro. Glia 62: 493-503. doi:10.1002/glia.22619

Namba Y, Tomonaga M, Kawasaki H, Otomo E, Ikeda K (1991) Apolipoprotein E immunoreactivity in cerebral amyloid deposits and neurofibrillary tangles in Alzheimer's disease and kuru plaque amyloid in Creutzfeldt-Jakob disease. Brain Res 541: 163-166. doi:10.1016/00068993(91)91092-f

Naslund J, Thyberg J, Tjernberg LO, Wernstedt C, Karlstrom AR, Bogdanovic N, Gandy SE, Lannfelt L, Terenius L, Nordstedt C (1995) Characterization of stable complexes involving apolipoprotein $\mathrm{E}$ and the amyloid beta peptide in Alzheimer's disease brain. Neuron 15: 219-228. doi:10.1016/ 0896-6273(95)90079-9

Nishitsuji K, Hosono T, Nakamura T, Bu G, Michikawa M (2011) Apolipoprotein $E$ regulates the integrity of tight junctions in an isoform-dependent manner in an in vitro blood-brain barrier model. J Biol Chem 286: 17536-17542. doi:10.1074/jbc.m111.225532 
Penzes P, Cahill ME, Jones KA, VanLeeuwen JE, Woolfrey KM (2011) Dendritic spine pathology in neuropsychiatric disorders. Nat Neurosci 14: 285-293. doi:10.1038/nn.2741

Pfrieger FW, Ungerer N (2011) Cholesterol metabolism in neurons and astrocytes. Prog Lipid Res 50: 357-371. doi:10.1016/j.plipres.2011.06.002

Pitas RE, Boyles JK, Lee SH, Foss D, Mahley RW (1987) Astrocytes synthesize apolipoprotein E and metabolize apolipoprotein E-containing lipoproteins. Biochim Biophys Acta 917: 148-161. doi:10.1016/00052760(87)90295-5

Pozueta J, Lefort R, Shelanski ML (2013) Synaptic changes in Alzheimer's disease and its models. Neuroscience 251: 51-65. doi:10.1016/j. neuroscience.2012.05.050

Reiserer RS, Harrison FE, Syverud DC, McDonald MP (2007) Impaired spatial learning in the APPSwe + PSEN1DeltaE9 bigenic mouse model of Alzheimer's disease. Genes Brain Behav 6: 54-65. doi:10.1111/j.1601183x.2006.00221.x

Schindelin J, Arganda-Carreras I, Frise E, Kaynig V, Longair M, Pietzsch T, Preibisch S, Rueden C, Saalfeld S, Schmid B, et al (2012) Fiji: An opensource platform for biological-image analysis. Nat Methods 9: 676-682. doi:10.1038/nmeth.2019

Seabrook TA, Burbridge TJ, Crair MC, Huberman AD (2017) Architecture, function, and assembly of the mouse visual system. Annu Rev Neurosci 40: 499-538. doi:10.1146/annurev-neuro-071714-033842

Spires TL, Meyer-Luehmann M, Stern EA, McLean PJ, Skoch J, Nguyen PT, Bacskai BJ, Hyman BT (2005) Dendritic spine abnormalities in amyloid precursor protein transgenic mice demonstrated by gene transfer and intravital multiphoton microscopy. J Neurosci 25: 7278-7287. doi:10.1523/jneurosci.1879-05.2005

Spires-Jones TL, Hyman BT (2014) The intersection of amyloid beta and tau at synapses in Alzheimer's disease. Neuron 82: 756-771. doi:10.1016/j. neuron.2014.05.004

Tai HC, Serrano-Pozo A, Hashimoto T, Frosch MP, Spires-Jones TL, Hyman BT (2012) The synaptic accumulation of hyperphosphorylated tau oligomers in Alzheimer disease is associated with dysfunction of the ubiquitin-proteasome system. Am J Pathol 181: 1426-1435. doi:10.1016/ j.ajpath.2012.06.033

Thevenaz P, Ruttimann UE, Unser M (1998) A pyramid approach to subpixel registration based on intensity. IEEE Trans Image Process 7: 27-41. doi:10.1109/83.650848

Trommer BL, Shah C, Yun SH, Gamkrelidze G, Pasternak ES, Ye GL, Sotak M, Sullivan PM, Pasternak JF, LaDu MJ (2004) ApoE isoform affects LTP in human targeted replacement mice. Neuroreport 15: 2655-2658. doi:10.1097/00001756-200412030-00020

Urbanc B, Cruz L, Le R, Sanders J, Ashe KH, Duff K, Stanley HE, Irizarry MC, Hyman BT (2002) Neurotoxic effects of thioflavin S-positive amyloid deposits in transgenic mice and Alzheimer's disease. Proc Natl Acad Sci U S A 99: 13990-13995. doi:10.1073/pnas.222433299

Vehmas AK, Kawas CH, Stewart WF, Troncoso JC (2003) Immune reactive cells in senile plaques and cognitive decline in Alzheimer's disease. Neurobiol Aging 24: 321-331. doi:10.1016/s0197-4580(02)00090-8
Walsh DM, Selkoe DJ (2007) A beta oligomers: A decade of discovery. J Neurochem 101: 1172-1184. doi:10.1111/j.1471-4159.2006.04426.x

Wang Z, Jackson RJ, Hong W, Taylor WM, Corbett GT, Moreno A, Liu W, Li S, Frosch MP, Slutsky I, et al (2017) Human brain-derived Abeta oligomers bind to synapses and disrupt synaptic activity in a manner that requires APP. J Neurosci 37: 11947-11966. doi:10.1523/jneurosci.200917.2017

West HL, Rebeck GW, Hyman BT (1994) Frequency of the apolipoprotein E epsilon 2 allele is diminished in sporadic Alzheimer disease. Neurosci Lett 175: 46-48. doi:10.1016/0304-3940(94)91074-X

Wisniewski T, Frangione B (1992) Apolipoprotein E: A pathological chaperone protein in patients with cerebral and systemic amyloid. Neurosci Lett 135: 235-238. doi:10.1016/0304-3940(92)90444-c

Yang CP, Gilley JA, Zhang G, Kernie SG (2011a) ApoE is required for maintenance of the dentate gyrus neural progenitor pool. Development 138: 4351-4362. doi:10.1242/dev.065540

Yang J, Ji Y, Mehta P, Bates KA, Sun Y, Wisniewski T (2011b) Blocking the apolipoprotein E/amyloid-beta interaction reduces fibrillar vascular amyloid deposition and cerebral microhemorrhages in TgSwDI mice. J Alzheimers Dis 24: 269-285. doi:10.3233/jad-2011-101401

Yang T, Li S, Xu H, Walsh DM, Selkoe DJ (2017) Large soluble oligomers of amyloid beta-protein from Alzheimer brain are far less neuroactive than the smaller oligomers to which they dissociate. J Neurosci 37: 152-163. doi:10.1523/jneurosci.1698-16.2016

Yang T, O'Malley TT, Kanmert D, Jerecic J, Zieske LR, Zetterberg H, Hyman BT, Walsh DM, Selkoe DJ (2015) A highly sensitive novel immunoassay specifically detects low levels of soluble Abeta oligomers in human cerebrospinal fluid. Alzheimers Res Ther 7: 14. doi:10.1186/s13195-0150100-y

Yeh FL, Wang Y, Tom I, Gonzalez LC, Sheng M (2016) TREM2 binds to apolipoproteins, including APOE and CLU/APOJ, and thereby facilitates uptake of amyloid-beta by microglia. Neuron 91: 328-340. doi:10.1016/j.neuron.2016.06.015

Zerbi V, Wiesmann M, Emmerzaal TL, Jansen D, Van Beek M, Mutsaers MP, Beckmann CF, Heerschap A, Kiliaan AJ (2014) Resting-state functional connectivity changes in aging apoE4 and apoE-KO mice. J Neurosci 34: 13963-13975. doi:10.1523/jneurosci.0684-14.2014

Zheng JY, Sun J, Ji CM, Shen L, Chen ZJ, Xie P, Sun YZ, Yu RT (2017) Selective deletion of apolipoprotein $\mathrm{E}$ in astrocytes ameliorates the spatial learning and memory deficits in Alzheimer's disease (APP/PS1) mice by inhibiting TGF-beta/Smad2/STAT3 signaling. Neurobiol Aging 54: 112-132. doi:10.1016/j.neurobiolaging.2017.03.002

Zlokovic BV (2011) Neurovascular pathways to neurodegeneration in Alzheimer's disease and other disorders. Nat Rev Neurosci 12: 723-738. doi:10.1038/nrn3114

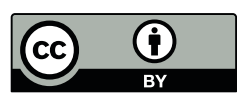

License: This article is available under a Creative Commons License (Attribution 4.0 International, as described at https://creativecommons.org/ licenses/by/4.0/). 